\title{
Linking remote sensing, land cover and disease
}

\author{
Paul J. Curran, Peter M. Atkinson, Giles M. Foody, \\ and Edward J. Milton.
}

\section{Department of Geography, University of Southampton,} Highfield, Southampton SO17 1BJ, UK

Table of contents

\subsection{Introduction}

2.2. A framework for the remote sensing of disease

2.3. From remotely sensed images of landscape to a multitemporal spectral mosaic

2.3.1. The scene model

2.3.2. The atmosphere model

2.3.3. The sensor model

2.3.4. The image model

2.4. From a multitemporal spectral mosaic to land cover

2.4.1. Mapping vegetation amount

2.4.2. Conventional classification approaches for land cover type

2.4.2.1. Unsupervised classification

2.4.2.2. Supervised classification

2.4.3. Problems with conventional classification approaches for mapping land cover type

2.4.4. Spectral unmixing

2.4.5. Soft or fuzzy classification

\subsection{Predicting vector density and disease risk from land cover data}

2.5.1. Predicting vector density or disease risk?

2.5.1.1. Choice of variables and predictive route 
2.5.1.2. Organising the primary variable

2.5.2. Sampling issues

2.5.2.1. Choosing a spatial resolution

2.5.2.2. Spatial sampling of the primary variable

2.5.3. Models for predicting vector density and disease risk

2.5.3.1. Temporal prediction: simple correlation on monthly averages

2.5.3.2. Spatial prediction: hard land cover classes

2.5.3.3. Spatial prediction: soft land cover classes

2.5.3.4. Spatial prediction: vegetation indices

2.5.3.5. Spatial prediction: GIS variables

\subsection{Discussion and conclusion}

\subsection{References}

\section{List of Tables}

\section{List of Figures}




\section{Abstract}

Land cover is a critical variable in epidemiology and can be characterised remotely. A framework is used to describe both the links between land cover and radiation recorded by a remotely sensed image and the links between land cover and the disease carried by vectors. The framework is then used to explore the issues involved when moving from remotely sensed imagery to land cover and then to vector density/disease risk. This exploration highlights the rôle of land cover; the need to develop a sound knowledge of each link in the predictive sequence; the problematic mismatch between the spatial units of the remotely sensed and epidemiological data and the challenges and opportunities posed by adding a temporal mismatch between the remotely sensed and epidemiological data. The paper concludes with a call for both greater understanding of the physical components of the proposed framework and the utilisation of optimised statistical tools as prerequisites to progress in this field. 


\subsection{Introduction}

The application of remote sensing to epidemiology is based on the development of a logical sequence that links measures of radiation made by a sensor on board an aircraft, or more usually a satellite, to measures of a disease and its vector (e.g., Crombie et al., 1999). At its most general, a sequence could be: (i) remotely sensed data can be used to provide information on land cover (e.g., different vegetation types or classes of vegetation amount) and thereby habitat (Innes and Koch, 1998), (ii) the spatial distribution of vector-borne disease $z$ is related to the habitat of that vector (Pavlovsky, 1966) and (iii) therefore, remotely sensed data can be used to provide information on the spatial distribution of vector-borne disease $z$ (Hay et al., 1997).

In certain circumstances the first two propositions can be well-founded. For example, where remotely sensed data and disease data are both related to climate (Hugh-Jones, 1991a; Thomson et al., 1996; Hay et al., 1996; 1998a). When this is the case researchers have sought to use remote sensing as a direct and instrumental tool (Curran, 1987) to predict and map the location of some of the major diseases affecting human health (Bailey and Linthicum, 1989; Hay et al., 1997; 1998b; Malone et al., 1997; Connor, 1999).

"Satellite (sensor) images can pinpoint the breeding grounds of the mosquitoes that cause malaria, pick out the tsetse fly's favourite haunts and perhaps even identify places where there is a risk of cholera" (K. Kleiner, 1995, p.9).

In support of such predictions research has been undertaken in different environments, for different diseases and vectors and with various combinations of imagery and ancillary data (Hugh-Jones and O'Neil, 1986; Hay et al., 1997; Estrada-Peña, 1998). Some thirty years of experience (Cline, 1970) have shown that while the remote sensing of disease is certainly viable (Linthicum et al., 1987; Hugh-Jones, 1991a; Rogers and Williams, 1993) it will not be a robust and reliable epidemiological technique until we have developed a sound understanding of all of the links between remotely sensed data and variables of epidemiological significance. This paper will attempt to provide a framework for this understanding that is focused on the rôle of land cover.

\subsection{A framework for the remote sensing of disease}

\section{[Figure 1]}

The logical sequence linking remotely sensed data to diseases and their vectors (Section 2.1) can be expanded into a framework (Figure 1). The framework highlights the links that span the gap between image(s) and disease; the rôle of land cover; the variation in space and time between image and disease and the simplifying assumptions that need to be made if remotely sensed data are to be used to predict the density of disease vectors or risk of disease, either directly or via the mapping of land cover (Curran et al., 1998). The permutations of imagery (Rees, 1999; Hay, 2000), land cover, disease vectors and types of disease in both space and time are enormous (Washino and Wood, 1994). To complicate matters further some diseases have vectors (e.g., dogs) that are not in themselves a risk to human health (Danson et al., 2000). However, to illustrate the preferred predicted model in the framework (Figure 1) only four permutations have been chosen (Table 1). In example one radiation in visible to middle

[Table 1] 
infrared wavelengths was recorded last month on several Landsat Thematic Mapper (TM) images for a region in South East Asia. The radiation measurements were pre-processed and then classified to produce a land cover map comprising water (home to mosquito larvae), pasture (location of cattle) and villages (location of people). The mix of land cover was, assuming little change, related to the number of mosquitoes at points now and thereby the number of people in the villages who could fall victim to malaria within the next month or so. In example two radiation in red (R) and near infrared (NIR) wavelengths was recorded last month on several National Oceanic and Atmospheric Administration (NOAA) Advanced Very High Resolution Radiometer (AVHRR) images for a country in Africa. Following image pre-processing the monthly maximum Normalised Difference Vegetation Index $(\mathrm{NDVI}=(\mathrm{NIR}-\mathrm{R}) /(\mathrm{NIR}+\mathrm{R}))$ was used to estimate and map the amount of green biomass for last month. The amount of green biomass would have been responding to the same climatic triggers as tsetse flies. Therefore, the amount of green biomass would have been related to the number of tsetse flies at points last month and thereby the number of people who would fall victim to sleeping sickness today. In example three backscattered microwave radiation was recorded during the winter and summer of last year on two Japanese Earth Resources Satellite (JERS-1) Synthetic Aperture Radar (SAR) images for a country in northern Europe. The images were pre-processed, classified and then used to produce a map of last year's deciduous forest cover. The area of deciduous forest cover would have been related to the number of tick carriers (deer, pheasants) and the total number of ticks on such carriers is known to peak in the spring. Therefore, the area of deciduous forest cover would be related to this year's point data on ticks in springtime and thereby will be related to the number of people who will fall ill with Lyme disease during this year's summer. In example four radiation in visible to near infrared wavelengths was recorded ten years ago on several Landsat Multispectral Scanning System (MSS) images for a region in central Asia. The images were pre-processed and then used to produce a land cover map comprising open shrub (wild vole habitat) and villages (people). The presence of open scrub cover within around $5 \mathrm{~km}$ of a village was likely to provide a suitable hunting ground for domesticated dogs that ingest the wild voles and their tapeworms. The tapeworms are excreted, some carry liver disease and the incubation time is around ten years. Therefore, the proportion of open shrub cover ten years ago would be related to the number of people in the villages who are now suffering with liver disease.

As these four simplified examples of prediction illustrate, there is no one methodology for the remote sensing of disease. The four examples, have used data from different satellite sensors, recorded for various areas, spatial resolutions and times in the past to both identify land cover (e.g., forests, pasture, cereal, urban) and quantify land cover (e.g., high or low biomass) that is linked, ultimately, to data on disease at the specific location recorded at some moment in time. The remainder of this text will restrict itself to data collected in optical (visible to thermal) wavelengths and although discussion will cover both the identification and quantification of land cover, emphasis will be on identification in which land cover is treated as a categorical rather than a continuous variable.

To emphasise the diversity that is encompassed by the framework (Figure 1) Table 2 lists fifteen contemporary studies, all of which have had to contend with a major mismatch in the spatial sampling units of remotely sensed and epidemiological data. These studies have a complete spatial coverage of remotely sensed data broken down into spatial sampling units of various size. The data for these units are then used to produce, or more usually infer, a contiguous but simple land cover representation that is, in turn, related to vector density or disease incidence data that tends to be spatially and numerically incomplete and misplaced spatially from the 
location of disease contraction.

[Table 2]

The links that are being employed in the framework (Figure 1), exemplars and examples (Tables 1 and 2) vary from the physical and well-understood link between radiation and an image to the empirical link between a vector in a field and say a patient in a hospital. As Table 2 indicates this latter link is weakest (Roberts et al., 1991) particularly in the developing world, if only because

"the most difficult data to obtain are reliable field data, especially of disease" (M. Hugh-Jones, 1991b, p.202-203).

For the next three stages of the paper we will explore, in detail, some of the more important facets of the framework (Figure 1).

We will start with a remotely sensed image, or images, of landscapes (Hay, 2000); and move to a possibly (multitemporal) spectral mosaic (Section 2.3) and thence to a map of land cover (Section 2.4). This will serve to illustrate the physical processes that link remotely sensed data to the landscape (Figure 1). Section 2.5 will move to the prediction side of the framework (Figure 1) and focus on the use of remotely sensed data to estimate vector density and disease risk.

\subsection{From remotely sensed images of landscape to a multitemporal spectral mosaic}

The preceding section established that land cover is a central issue in the use of remote sensing in epidemiology, whether explicitly, through the relationship between vectors and their habitat, or implicitly, through the use of remote sensing to provide proxy ecological indicators such as the NDVI (Table 1) (Crombie et al., 1999). Whether in the tropics or the temperate zone, the focus of epidemiological interest usually concerns landscapes in which green vegetation, bare soil and water are present. The interaction between these generalised land covers, either through time or across space is central to understanding ecological and therefore disease dynamics using remote sensing.

The source of remotely sensed data for epidemiological research is typically one or more digital images of part of the Earth's surface. The aim of this section is to show how reliable data on the reflectance properties of the Earth's surface may be derived from such images. We begin by breaking down what can be termed the "remote sensing information system" into four linked models (Figure 2): scene model, sensor model, atmosphere model and image model. The scene model is a representation of the Earth's surface that acts as the gateway between the information domain (i.e., the biophysical properties of the real world that we are interested in) and the data domain (i.e., spatial patterns and temporal fluxes of electromagnetic radiation). The sensor model and atmosphere model are certainly relevant to the epidemiologist, but are less accessible or open to 
modification because they are physically-based or determined by engineering decisions made by data providers. The image model is the output of the system and makes the necessary translation back from the data domain to the information domain. There are as many different information domains as there are users, so there are many possible image models. Some properties of the image model may be fixed by system parameters (e.g., images from a given sensor have a given pixel size), but others may be under the control of the user ( $e . g$., the bands may be programmable or only a few are selected).

[Figure 2]

The aim of the remote sensing information system shown in Figure 2 is to address questions such as "What is the land cover at point $a$ ?", "Has it changed from last month?", and "How much of material $b$ (e.g., green biomass) is there at point $c$ ?". To understand how to optimise the remote sensing information system to answer such questions accurately and to appreciate its limitations as well as its possibilities, it is necessary to consider each of the four models in turn (scene, atmosphere, sensor, image) and we will do this by following the flow of data through the system from the scene comprising a landscape of different land covers to the image(s) used by the epidemiologist (Figure 1).

\subsubsection{The scene model}

The interaction of electromagnetic radiation with various components of the landscape is very complex (Curran et al., 1998). Spectral measurements of individual leaves made using laboratory spectrophotometers have proved to be useful aids for understanding interactions between electromagnetic radiation (EMR) and plant materials, but they are insufficient in themselves to explain the spectral reflectance of a plant canopy comprising leaves, branches, shadow and soil background (Colwell, 1974). Vegetation canopies comprise many individual scene components (e.g., leaves, stems, flowers) arranged throughout a three-dimensional volume which is difficult to simulate in the laboratory. Furthermore, in the "real world", a vegetation canopy is situated within a particular radiation environment comprising direct illumination from the Sun and diffuse illumination from skylight. Accurate simulation of the illumination geometry and spectral distribution of sunlight is exceptionally difficult to achieve in the laboratory. The same limitations affect our understanding of the reflectance of bare soil surfaces. Whilst it is relatively easy to measure the spectral reflectance of crushed or powdered samples in the laboratory there is ample evidence to confirm that one of the primary influences on soil reflectance is surface roughness, through its influence upon shadowing (Irons et al., 1992). These problems may be addressed either by measuring the spectral reflectance of plant canopies and soils in the "real" radiation environment (in the 
field) (Milton, 1987) or by using computer modelling to simulate their reflectance properties of appropriate scene components within a virtual radiation environment (Goel, 1988).

Passive remote sensing systems use the Sun as an energy source, thus the position of the Sun in the sky at the time of sensing controls which scene components are illuminated and the location and extent of shadows. The geometric variables associated with remote sensing measurements are defined in Figure 3. The threedimensional

\section{[Figure 3]}

nature of vegetation canopies means that the contribution of different canopy components to spectral reflectance varies depending upon the angle at which the canopy is viewed and illuminated. For a forest or shrub canopy, for example, the proportion of green leaves presented to a remote sensing system increases as the view angle from nadir $\left(?_{r}\right)$ increases, whereas the proportion of shadow decreases. The combined dependence of the reflected flux upon the zenith and azimuth angles of the sensor $\left(?_{r}, ?_{r}\right)$ and those of the Sun $\left(?_{i}, ?_{i}\right)$ is recognised by the use of the prefix "bidirectional" to describe spectral reflectance measurements made in the field environment (Milton, 1987). Bidirectional reflectance is an intrinsic property of the surface and is defined as the ratio of energy reflected from the surface when illuminated by direct light from the Sun as a proportion of that which would be reflected from a perfectly diffuse, $100 \%$ reflecting, surface at the same location. A single measurement of bidirectional reflectance is actually the integration over the solid angle subtended by the sensor of a more fundamental property: the "bidirectional reflectance distribution function" (BRDF) (Nicodemus et al., 1977).

\subsubsection{The atmosphere model}

The interaction between electromagnetic radiation and the atmosphere is very complex. Several different strategies for reducing or "correcting" for the influence of the atmosphere upon remotely sensed data have been developed, however (Teillet et al., 1990). Different methods are appropriate depending upon the region of the electromagnetic spectrum being sensed, the altitude and orbit of platform being used, the availability of ancillary information and the level of accuracy required. For some epidemiological applications, the main concern is monitoring or detection of land cover change, in which case absolute accuracy (e.g., unbiased and precise measurements of ground-leaving radiation in physical units of spectral radiance) may be less important than the repeatability of the measurements.

Atmospheric correction procedures range from methods based solely on image data (e.g., Chavez, 1996), 
to vicarious methods which require measurements from the ground surface at the time of sensor overpass (Slater et al., 1984), to methods which use the geometry of viewing to infer the effect of the atmosphere (e.g., Mackay et al., 1998), to physically-based radiative transfer models (e.g., Tanré et al., 1990).

\subsubsection{The sensor model}

Most electro-optical sensors are designed to have a wavelength-specific linear relationship between the physical variable being measured (e.g., radiance or temperature) and the digital number (DN) value. Satellite sensors are calibrated in the laboratory before launch but are prone to drift over time following the trauma of the launch and as the exposed optical surfaces degrade in the space environment. Measurements from spectrally-stable desert environments have been used to derive a correction factor for the NOAA AVHRR sensor based on the number of days since launch and other schemes proposed for the Landsat sensors include using the Moon as a stable reference target (Kieffer and Wildey, 1985). Depending upon how the data are to be used, it may not be necessary, or indeed desirable, to convert DN to values of radiance. The results from even simple analytical techniques, however, such as the use of multispectral ratios (e.g., NDVI) may require that values of relative DN are converted to absolute radiance and in addition, correction is made for the effect of the atmosphere (Crippen, 1988).

\subsubsection{The image model}

The three-dimensional $(\mathrm{x}, \mathrm{y}, \mathrm{z})$ spatial assemblage of scene components constitutes the scene model from which the remote sensor draws its measurements. The resulting image is a representation of the scene at a particular moment in time and the degree to which the complexity of the scene is captured in the image depends upon the size of the scene components in relation to the instantaneous field-of-view (IFOV) of the sensor and their spectral contrast with each other (e.g., between canopy and background). At one extreme are scenes composed of spectrally-distinct, temporally-variable objects larger than the IFOV and at the other are scenes composed of spectrally-indistinct, temporally invariant objects smaller than the IFOV. Strahler et al. (1986) described these extremes and showed how the image model chosen influences the subsequent analysis and the conclusions derived.

There are many image models which are potentially useful for epidemiological remote sensing but before giving some examples of these we should note the trade-off which occurs in satellite remote sensing between the revisit interval of the satellite and the IFOV of the sensor. For example, a single NOAA satellite has a revisit 
interval of 12 hours and so provides two AVHRR images per day of a site but these have a fairly coarse spatial resolution (nominally $1.1 \mathrm{~km}$ ). By contrast a Landsat satellite has a revisit interval of 16 days but carries the TM which provides data with a fairly fine spatial resolution (nominally $30 \mathrm{~m}$ in all except thermal wavelengths). Two other features of satellite sensor data are relevant in an operational context: the size of area covered by a single image and the total length of the observation record.

Most epidemiological research that has used remote sensing has been based on a very restricted set of wavelengths; often just two bands, one in the red part of the spectrum and one in the near infra-red (e.g., example two in Table 1). These are well-established regions for the study of vegetation, although the physical interpretation of the commonly-used NDVI is still problematic (e.g., Sellers, 1987; Verstraete and Pinty, 1996). For example, some researchers would prefer to include green wavelengths instead of red to avoid problems of radiation saturation when recording large amounts of biomass (e.g., Gitelson et al., 1996) or middle infrared wavelengths instead of red to increase sensitivity to canopy water content (Boyd and Curran, 1998).

The power of spectroscopy as a tool to investigate and classify materials is well-established in the laboratory and this is now being extended to sensors on board aircraft and satellites (Curran et al., 1997; Verstraete et al., 1999). Airborne imaging spectrometers have been developed which can provide images of the Earth's surface in which each pixel contains a complete reflectance spectrum over a broad spectral region in hundreds of contiguous spectral bands (Curran, 1994). Spaceborne spectrometers have been demonstrated (Goetz et al., 1982) and imaging spectrometers will soon be operational on satellites to be launched by the NASA and the European Space Agency. Eventually, it may be possible to use data from such systems in physically-based plant growth models, since imaging spectrometry offers the possibility of measuring directly the biochemical (e.g., lignin and cellulose) composition of plant canopies (Curran, 1989).

The advent of spaceborne imaging spectrometers raises a key question of how many bands are required in order to capture the land cover information of relevance to epidemiology? The strong correlation between spectral bands means that the intrinsic dimensionality (Curran et al., 1998) of such data is much less than the number of bands might suggest. Of 224 bands acquired by the Airborne Visible/Infrared Imaging Spectrometer (AVIRIS) from a vegetated landscape in California, Boardman (1994) found the data could sometimes be represented within as few as four independent dimensions. This result accords with those from other studies, including work by Price (1990) which approached the same problem using spectra measured in the field, and it seems likely that most spectral information from vegetation and soils can be captured by relatively few spectral features (Curran et al., 1998). These features may be discrete spectral bands or they may be combinations of 
bands, such as the NDVI.

Although the spectral requirements of epidemiological remote sensing are quite modest, the spatial and temporal requirements are much more demanding, particularly if progress is to be made towards linking remotely sensed data to the rates rather than the outcomes of ecological processes. Traditional land cover surveys using remote sensing provide a static view of the Earth's surface. Some may include information on the seasonal variability of classes, however, by combining data collected at different times of the year but they do not, in general, capture the dynamic processes which drive the biological system and therefore are important in epidemiology, such as plant phenology, temperature change and rainfall input (Roughgarden et al., 1991). To study plant canopy and landscape dynamics over timescales that are relevant to epidemiology it is necessary to acquire remotely sensed data at frequent time intervals. In theory, this is possible with sensors carried on Earth resources satellites such as Landsat or SPOT (Rees, 1999). In practice, however, at least for the humid tropics, the high probability of cloud cover and the 16-day or longer revisit period conspire to make this unlikely (Foody and Curran, 1994). The pointing capability of the SPOT HRV and the future availability of many more Earth resources satellites will increase data availability, though probably at the expense of increased problems of data inter-calibration.

For many years now researchers have used low cost NOAA AVHRR data to study vegetation phenology at regional to global scales (Justice et al., 1985). The few spectral bands available from this sensor are suited to monitoring vegetation and the twice daily revisit interval greatly increases the chance of obtaining cloud-free data at the time of the year when they are required. The finest spatial resolution image model which is possible using such data is $1.1 \mathrm{~km}$, but this need not be the ultimate limit to the information content of such data An image model developed at any spatial resolution always has the potential to be used to estimate the within-pixel proportions of objects smaller than a pixel in size, using techniques such as the spectral unmixing described by Adams et al. (1993). Pixel unmixing is used widely in remote sensing for mineral exploration and regional and global scale mapping of fractional vegetation cover (Adams et al., 1995) but although it has much to offer (Crombie et al., 1999), it has been little used in epidemiology (see discussion in Section 2.4).

This section has discussed the links between land cover and an image or images and in doing so reference has been made to models of the scene, atmosphere, sensor and image. To make predictions using remotely sensed data we need to reverse this sequence. The first step is to remove as many extraneous factors as possible from the remotely sensed measures of radiation by means of radiometric, atmospheric, geometric and perhaps even topographic correction (Richards, 1993; Schowengerdt, 1997; Cracknell, 1997; Mather, 1999a; 
Barrett and Curtis, 1999). This will enable the production of a spectral mosaic of the landscape. The next step is to turn this single date or multitemporal spectral mosaic into map(s) of land cover properties.

\subsection{From a multitemporal spectral mosaic to land cover}

The production of a map of land cover type is based on the existence of a specific spectral response for each land cover class. To enhance the ability to classify land cover accurately it is, therefore, important that, as far as possible, only the land cover and not some characteristic of say, the sensor or atmosphere, influence the remotely sensed response derived from the imagery (Figure 1). That is, the digital number (DN) or tone of a pixel in a particular waveband should be related directly to the magnitude of the radiation measured from the area represented by the pixel in that waveband. Furthermore, since the end product is a thematic map depicting land cover type (e.g., different vegetation types of classes of vegetation amount) it is often desirable to alter the image geometrically to a suitable map projection. Since the temporal dimension of remote sensing can be beneficial, if not essential, to some epidemiological studies (Hugh-Jones, 1989; Riley, 1989; Hay et al., 1997), especially in relation to prediction and control activities (Linthicum et al., 1999), the need to correct the imagery such that one image can be compared to another should be seen as important and fundamental to the use of remotely sensed data. Therefore, as was noted at the end of Section 2.3, the basis for epidemiological research should not be an image of a landscape but a carefully corrected spectral mosaic of that landscape at one or more points in time. This spectral mosaic may then be used to derive maps of land cover. In epidemiological studies the desire can be to either map land cover type (e.g., forest, pasture, cereal, urban) or some quantitative series of land cover classes (e.g., high, medium and low biomass) (Section 2.3, Tables 1 and 2). This section outlines the identification of land cover type and quantification of land cover amount from remotely sensed imagery, reviewing conventional and widely used approaches, as well as illustrating some recent developments in the field. However, the emphasis here, and in the sections that follow, is on the identification of land cover type in which land cover is treated as a categorical rather than a continuous variable.

\subsubsection{Quantifying land cover (e.g., vegetation amount)}

The amount of vegetation, expressed typically in terms of biomass or leaf area index (LAI), has a strong relation to variables of epidemiological significance (Table 1). Consequently, maps of vegetation amount may be used in epidemiological studies as a surrogate variable for key environmental conditions or variables associated with diseases (Figure 1). Thus, for example, many studies have utilised vegetation indices, such as the NDVI, that 
are both physically related and correlated strongly with vegetation amount (Cross et al., 1996; Hay et al., 1997; Linthicum et al., 1999; Thomson et al., 1999). For some quantitative analyses and comparison between studies or over time it is essential that vegetation indices be calculated from appropriately pre-processed imagery (Price, 1987; Guyot and Gu, 1994; Mather, 1999a). The vegetation index image derived from the remotely sensed data may be interpreted as a map depicting vegetation amount as a continuous variable. Alternatively, a set of vegetation index thresholds may be defined to map discrete classes of vegetation amount (Curran, 1983). Although simple, such approaches can yield information of epidemiological interest. For example, vegetation amount at a local scale is often related to climate whereas at the regional scale it is often related to broad classes of land cover (Table 1). The accuracy of vegetation amount maps may be evaluated if ground data on vegetation amount are available (Curran and Williamson, 1985). The mapping of vegetation amount or more usually a surrogate, is well developed in regional scale epidemiology (Hay et al., 1997). To understand the processes that underpin the pattern of diseases and their vectors, however, it may be necessary to map the land cover type and this necessitates classification. The remainder of this paper will therefore concentrate on the identification and mapping of land cover type.

\subsubsection{Conventional classification approaches for mapping land cover type}

Classification techniques are used typically in the mapping of land cover type from remotely sensed imagery. This applies to both mapping based on visual and digital analysis of the imagery. Visual analysis makes use of the ability of the human eye-brain system to interpret imagery rapidly and accurately. The identification of land cover type is based generally on the use of tonal, textural and contextual information often with the aid of a classification key that gives illustrative examples of the appearance of the land cover classes (Barrett and Curtis, 1999; Lillesand and Kiefer, 1999; Kelly et al., 1999). This approach has been used frequently in epidemiological studies. Visual interpretation of remotely sensed imagery, including aerial photographs and satellite sensor images, has, for example, been used in the surveillance and control of arthropod vectors (Riley, 1989; Washino and Wood, 1994). Although visual interpretation is still used widely and can be accurate, it is not without problems. Key concerns are subjectivity in the interpretation; difficulty of handling the large multispectral data sets acquired by many remote sensors and the problem of maintaining a standardised classification over time and space (Philipson, 1987). Computer-based mapping techniques can make fuller use of the data set and be undertaken in a more objective manner. In addition, digital analysis eases integration of the imagery and derived map data with other digital spatial data sets within a geographical information system 
(GIS) aiding the development of relations between the environment and variables associated with diseases (Rejmankova et al., 1995). Digital image classification is one of the most commonly performed analyses of remotely sensed imagery (Jensen, 1996). As with visual interpretation it aims to convert the image into a thematic map and to this end two broad approaches are used; supervised and unsupervised.

\subsubsection{Unsupervised classification}

Unsupervised classifiers are effectively clustering algorithms that seek spectral clusters in the imagery. The classification algorithm groups together pixels with similar spectral properties and gives them a class label (e.g., forest). Since the identification of land cover type classes requires class-specific spectral responses an unsupervised classifier may be expected to identify land cover classes. This approach to classification has been used widely in the identification of land covers and habitats associated with intermediate hosts and disease vectors (Hugh-Jones, 1991a; Beck et al., 1994; Pope et al., 1994; Rejmankova et al., 1995; Thomson et al., 1999). A major problem with unsupervised classification, however, is that the analyst must relate the clusters defined by the classification to the land cover type after the classification and there is no guarantee that the clusters will correspond to land cover classes of epidemiological significance. Since the classes of interest are often well-known (e.g., those that represent habitats associated with particular hosts or disease vectors) an unsupervised classification is often inappropriate and a supervised classification should be used.

\subsubsection{Supervised classification}

A supervised classification uses examples of the land cover classes, derived typically from within the imagery, to direct the classification algorithm (Lillesand and Kiefer, 1999; Campbell, 1996; Mather, 1999a). This is useful as the land cover classes and/or habitats of disease vectors are often known (Riley, 1989; Hugh-Jones, 1989; Hay et al., 1997) and consequently this approach has been used in epidemiological studies (e.g., Hayes et al., 1985). The classification comprises three key stages. First, the training stage in which sites of known land cover class are identified in the image and characterised spectrally. The end product of this stage is a set of training statistics that describe the spectral properties of the classes to be mapped. The second stage of the classification involves the use of training statistics together with a classification algorithm to allocate each pixel in the image to a land cover class. This involves typically a comparison of the pixel's spectral properties with those of the classes derived in the training stage and allocation of the pixel to the class with which it has greatest similarity. In this way, the remotely sensed image is converted into a thematic map depicting the spatial distribution of the land cover classes of interest. The final stage of the classification is the testing stage in which 
the accuracy of the classification is assessed. This aims typically to derive a quantitative measure of the accuracy with which land cover has been mapped. Classification accuracy is evaluated generally from a crosstabulation of the actual and predicted class membership of a set of pixels that were not used in training the classification (Figure 4). The end product of the supervised classification is, therefore, a map of known accuracy that depicts the spatial distribution of land cover classes of interest.

[Figure 4]

Although a popular means of deriving maps of land cover type, many factors affect the accuracy of a supervised classification and so too its utility for epidemiological studies. A series of such factors may be associated with each stage of the classification (Campbell, 1996; Arora and Foody, 1997; Foody and Arora, 1997). Much attention has focused on issues concerned with the classification algorithm used. To-date the majority of digital image classifications have used a conventional statistical classification algorithm. Probabilistic techniques such as the maximum likelihood classifier and discriminant analysis have been particularly popular. These approaches have firm statistical foundations and allocate each case (e.g., pixel) to the class with which it has the highest probability of membership (Peddle, 1993; Mather 1999a). Although this is an intuitively appealing approach and can be accurate, the correct application of such classifications requires the satisfaction of several assumptions that are not always tenable (Section 2.4.3) and it is sometimes difficult to integrate ancillary data into the analysis. Moreover, it has often proved difficult to produce reliably maps of land cover type with an accuracy that is acceptable operationally (Townshend, 1992). Consequently, considerable attention has been directed at the development and evaluation of alternative classification approaches. This has included the use of a range of non-parametric classifiers, with approaches based on evidential reasoning or neural networks proving popular (Srinivasan and Richards, 1990; Benediktsson et al., 1990; Fischer et al., 1997). Comparative studies using a suite of classification methods have shown repeatedly that for the majority of imagery and landscapes, neural networks can provide the most accurate classification of land cover (Benediktsson et al., 1990; Peddle et al., 1994; Paola and Schowengerdt, 1995). From the range of network types, feedforward networks such as the multi-layer perceptron are now the most used in mapping land cover type from remotely sensed data (Figure 5). This network uses a learning algorithm (e.g., backpropagation) and the training set to adjust its internal properties until it can identify accurately the land cover classes of interest from the remotely sensed imagery (and any available ancillary data) presented to it.

[Figure 5]

2.4.3 Problems with conventional classification approaches for mapping land cover type 
Despite the considerable advances made in the development of classification algorithms, including neural networks, the accuracy of land cover type maps derived from remotely sensed imagery is still often insufficient for operational application (Wilkinson, 1996). Further increases in accuracy may be made by refinements to the training and testing stages of the classification (e.g., training set refinement to remove or down-weight ambiguous training samples, acquisition of larger training and testing sets). A major limit to the accuracy of digital image classifications has, however, been the tendency to use only spectral information in the classification (Curran et al., 1998). The classifications have, therefore, tended to use only the amount of radiation recorded for each pixel in each spectral waveband to discriminate between land cover types. Thus, while human interpretation uses tone, texture and context most digital image classifications have used only tonal information which may be relatively uninformative. Image texture, which describes simply the local variability of image tone, can be quantified with relative ease from remotely sensed imagery (Mather, 1999a). Popular measures of image texture range from simple measures of tonal variability within a local window, particularly those based on grey level co-occurrence matrices (Haralick and Shanmugam, 1974; Holmes et al., 1984) through to geostatistical descriptors of the local variability of image tone (Miranda and Carr, 1994; Berberoglu et al., 2000; Lloyd et al., 2000). Context describes a range of features such as the size, shape and location of objects to be classified. Although it is difficult to quantify context from remotely sensed imagery it may be used to increase significantly the accuracy with which land cover type is mapped (Gurney and Townshend, 1983; Harris, 1985; Groom et al., 1996). In addition to image based information there may be various ancillary data that can enhance class separability. For example, ancillary data on altitude or soil type may help discriminate vegetation communities that have a similar appearance in the imagery but are known to be located in different environments. The integration of ancillary information into the analysis has often been found to increase the accuracy of a variety of classifications (Strahler, 1980; Hutchinson, 1982; Peddle et al., 1994). Despite these refinements to the techniques available no classification is ideal, this is because there remain several fundamental problems with classification as a tool for land cover mapping (Foody, 1999; Mather, 1999b).

Classification, by whatever method, makes several basic assumptions. Two critical assumptions, of relevance here, are that each case to be classified is pure (i.e., represents an area on the ground covered by a single class) and that the classes to be mapped are discrete and exclusive mutually. Both of these basic assumptions are often unsatisfied when mapping land cover type from remotely sensed imagery. Often, for example, pixels of mixed land cover class composition may be abundant in an image. Thus, for instance, vegetation classes may be continuous and inter-grade gradually with many areas of mixed class composition, particularly near 
imprecise or "fuzzy" class boundaries. Alternatively, as a pixel is an arbitrary spatial unit, the size, shape and location of which is dependent more on the properties of the sensor than the land surface, it may represent an area on the ground that comprises more than one discrete land cover class. This often occurs when the area represented by the pixel straddles the boundaries of two or more classes and is common in landscapes composed of small spatial units and/or when using coarse spatial resolution imagery (Crapper, 1984; Campbell, 1996). Irrespective of the origin of the land cover type mixture, mixed pixels are a major problem, as a conventional supervised classification algorithm will force the allocation of a mixed pixel to one class, which need not even be one of the component classes (Campbell, 1996). Since the conventional classification output is "hard", comprising of only the code of the allocated class, such techniques cannot, therefore, be used appropriately to represent the land cover type of the area represented by a mixed pixel. As the proportion of mixed pixels in an image can be very large (the exact proportion of mixed pixels in an image is a function of the sensor's spatial resolution and the size of the spatial units in the landscape), this can be a major problem in the production of accurate maps of land cover type from remotely sensed data. Moreover, the errors in the representation of land cover type may also propagate into analyses based on the map. This includes the evaluation of change in land cover type through post-classification comparison methods and analyses using co-registered data sets within a GIS. Problems associated with mixed pixels are usually apparent when using coarse spatial resolution data sets. These data sets however are often used for mapping land cover type at regional to global scales, because (i) remote sensing is the only feasible source of data on land cover type at such scales, or (ii) there is a need to monitor change in land cover type at a high temporal frequency. Some epidemiological applications (Table 2) have focused on relatively small areas and used fine spatial resolution imagery (e.g., from the SPOT HRV and Landsat TM) and so problems associated with the presence of mixed pixels would have been reduced but not removed. As has been mentioned, however, the more heterogeneous and fragmented the landscape and/or the coarser the spatial scale of study and imagery used the more significant and detrimental will be the effect of mixed pixels. Methods to appropriately represent land cover when mixed pixels are common are, therefore, required if the full potential of remote sensing as a source of data on land cover type is to be realised. Two commonly used methods are spectral unmixing and soft or fuzzy classification.

\subsubsection{Spectral unmixing}

Spectral unmixing is likely to be of direct relevance to the use of remotely sensed data in epidemiology. This is because contemporary sensors onboard the NASAs Terra or the ESAs Envisat have a ground resolution that 
represents areas in the order of tens of hectares and yet epidemiologists may wish to use such data to derive the land cover of fields only a few hectares in size. The principle of spectral unmixing may be illustrated easily by reference to the early technique of Adams et al. (1993). This technique makes certain simplifying assumptions about the scene. First, that the scene is composed of a geometric arrangement of identifiable components, such as green leaves, bare soil and shadow; second, that energy only interacts with one of these components on its passage from the Sun to the sensor and third, that the reflectance properties of the different components are known, either from data acquired in the field or laboratory, or from measurements made from the scene itself. We can, for example, use these data on the spectral properties of the scene components to determine the optimum "feature space" (Curran et al., 1998) to unmix the data, which is one in which the components are most separated from each other, as is shown diagrammatically in Figure 6. In practice, the optimum feature space would most likely be composed of combinations or mathematical transformations of radiation in wavebands measured by the sensor. Within the optimum feature space the data from the scene mix together within a subspace, the vertices of which are known as "endmembers". The relative proportion of endmembers within a pixel may then be calculated using its location within the mixing subspace (Figure 6). Endmembers may be of two types, depending upon whether they are defined from pure components of the image (image endmembers, such as a particular set of radiation values) or pure components of the scene (reference endmembers, such as trees, water, grass) (Milton, 1999). This process of spectral unmixing may be described mathematically as,

$$
\mathbf{r}_{i}=\sum_{j=1}^{n} a_{i j} f_{j}+e_{i}
$$

in which $\mathrm{r}_{i}$ is the reflectance of the pixel in band $i$ of $m$. The total number of components within the pixel is $n, f_{j}$ is the proportion of endmember $j$ in the pixel, and $a_{i j}$ is the reflectance of endmember $j$ in spectral band $i$. The term $e$ is an error term which expresses the difference between the observed reflectance and the reflectance computed from the model (Mather, 1999a).

To solve the pixel unmixing equation given above, the total number of components within the pixel must be no more than $n+1$, where $n$ is the number of spectral features (i.e., dimensionality of the mixing space). Whilst this limitation can be a problem in some applications (e.g., mineral exploration), for epidemiological research this would still allow the unmixing of green vegetation, soil background and water (or shadow) from a feature space which contains only two-dimensions. Because of the strongly contrasting spectral properties of 
vegetation, water, and most types of soil it is reasonable to expect any satellite sensor with bands in R and NIR wavelengths to be able to generate a suitable 2-D feature space.

Roberts et al. (1998) have modified the basic unmixing model described above by allowing the set of endmembers against which a given mixed pixel is labelled to vary across the image. This has the effect of permitting many more than the theoretical limit of $n+1$ scene components to be estimated, making it feasible to map the proportions of different types of vegetation, or live versus dead vegetation even though the data are distributed in relatively few dimensions. Spectral unmixing, however, is not the only way to deal with the problems of mixed pixels.

[Figure 6]

\subsubsection{Soft or fuzzy classification}

Since the conventional (hard) classification output cannot always represent the continuous graduation of some land cover types or mixing of classes within the area represented by pixel, alternative approaches have been sought (Wang, 1990). Much attention has focused on the potential of soft or fuzzy classifications that allow a pixel to have partial and multiple class membership (Wang, 1990; Foody, 1996; Bastin, 1997). There are a variety of methods for deriving a fuzzy classification. The most obvious are a range of fuzzy classifiers that can be used to derive estimates of sub-pixel scale class membership (Cannon et al., 1986). Alternatively, a fuzzy classification may be achieved by "softening" the output of a "hard" classification. For instance, measures of the strength of class membership, rather than just the code of the most likely class of membership, may be output. Thus, for example, with a maximum likelihood classification a probability vector containing the probability of membership a pixel has to each defined class could be output. In this probability distribution, the partitioning of the class membership probabilities between the classes would, ideally, reflect the land cover composition of a mixed pixel (Foody et al., 1992; Foody, 1996). This type of output makes fuller use of the information on class membership generated in the classification and may be considered to be fuzzy, as an imprecise allocation may be made and a pixel can display membership to all classes. The remotely sensed data must still, however, satisfy the assumptions and requirements of the classification technique used, which is often unlikely with the widely used probability-based classifiers. The lack of distribution assumptions and ability to integrate ancillary data acquired at a low level of measurement precision are major attractions of alternative classifiers such as neural networks. Although used generally to produce a hard classification the output of an 
artificial neural network may be softened to provide measures of the strength of class membership which may sometimes better represent land cover than a traditional "hard" classification (Foody, 1996).

Although fuzzy classifications have been used to provide an appropriate representation of land cover type that may be considered to be fuzzy, they do not fully resolve the mixed pixel problem (Foody, 1999). A fuzzy classification provides only a means of appropriately representing land cover type that may be considered fuzzy at the scale of the pixel. Thus, while the class allocation made by a fuzzy classification may accommodate appropriately mixed pixels it is only one of the three stages of the supervised classification process, with the classification still requiring training and testing. Relatively little attention has focused on the accommodation of mixed pixels in the training and testing stages of a supervised classification. In both of these stages of the classification, the ground data on class membership are generally related to the remotely sensed data at the scale of the pixel and so may be fuzzy. Since a large proportion of image pixels may be mixed it is important that this be recognised and accommodated in the classification. In testing the classification, for example, pure pixels are used generally as the conventional measures of accuracy assessment were designed for application to "hard" classifications. As the majority of pixels may be mixed failure to include them in the accuracy assessment may result in an inappropriate and inaccurate estimation of classification accuracy. A variety of methods may be used to accommodate for fuzziness in the classification output (Gopal and Woodcock, 1994; Maselli et al., 1994) and, under certain circumstances, in the ground data as well (Foody, 1996). Indeed methods exist to accommodate mixed pixels in each stage of the classification (Foody and Arora, 1996; Foody, 1997). The degree to which fuzziness is accommodated in each stage may also vary (e.g., the classification output could be the degree of membership to each class or a crisper product comprising the most likely class of membership and a secondary class label). Consequently, a classification may be undertaken along a continuum of classification fuzziness (Foody, 1999) ranging from the conventional "hard" classification, in which no action is made to accommodate mixed pixels, to fully-fuzzy classifications, in which mixed pixels are accommodated in each stage. The design of a classification should, therefore, be based on the nature of the available data sets as well as on the desired end product. The derived map of land cover type may then be integrated with, typically point based, data on disease and disease vectors. Relationships between land cover and disease variables may then be established from these data. These relationships may then be extrapolated spatially (and, if a time series of imagery is available, temporally) using maps of land cover type derived from remotely sensed imagery.

These two sets of links from land cover to image and land cover to disease (Figure 1) are fundamental to our understanding of how remote sensing can be used in epidemiology. However, in many cases these links 
become secondary to the primary pragmatic task of using remotely sensed imagery to estimate the density of disease vectors and the degree of disease risk. The remainder of this paper will therefore build on this background on process (Sections 2.3 and 2.4) and focus on the task of prediction. In doing so a number of recommendations will be made for best practice in the remote sensing of vector density and disease risk.

\subsection{Predicting vector density and disease risk from land cover data}

As outlined in the introduction, and summarized in Figure 1, a complex set of inter-relationships exist between remotely sensed imagery of the land surface and disease risk distributed spatially on that land surface. We have seen in previous sections that as the amount of radiation reflected (at a given wavelength) from a given point on the Earth's surface depends on the nature of the material (land cover type) at that point, it is possible to predict land cover spatially from remotely sensed imagery. This prediction usually depends on knowledge (data) of the in situ land cover via a model of the relation between the imagery and the land cover. This spatial prediction of land cover is based on explicit physical processes (Figure 1). Similarly, the links between other environmental variables that have been employed in the remote sensing of disease risk (e.g., cold cloud duration, CCD, Hay et al., 1996) and remotely sensed imagery are based on physical processes.

The link between land cover and vector density (or disease risk) is based on processes that are less easily described in terms of the physics of the processes involved, but which may be described well by stochastic models. Clearly, there are many different types of disease and vector. In recent years, much research has been undertaken on the use of remotely sensed data to predict malaria and trypanosomiasis risk (Table 2) and for ease of presentation the following section will focus mainly on the malaria-mosquito disease-vector combination (Horsfall, 1955). As suggested by the dashed predictive lines in Figure 1, it is useful to describe, first, the link between land cover and vector density and, second, the link between vector density and disease risk.

Unfortunately, the relations between land cover and vector density are not well understood in the majority of cases. Most studies describe the relations between habitat (which may or may not be synonymous with land cover) and vector (Legters, 1994). It is generally accepted, however, that for common vectors (such as various species of mosquito) proximity to water is important, particularly in the breeding phase. Habitats (represented as land covers or combinations of land covers) that are favourable to mosquitoes tend to be aquatic (e.g., brackish water, salt marsh) or at least close to water bodies. However, the physical processes underlying the link between land cover and vector density will, in practice, depend on (i) internal processes relating to the population, (ii) interelations between the vector and vertebrate populations and (iii) many environmental 
influences, particularly microclimatic variables that may be difficult to measure.

The relation between vector density and disease risk is yet more complex. For example, mosquitoes depend on vertebrates for blood which may, or may not, carry a disease (say, malaria). The vectors take up the disease and may, or may not, pass it on to the next vertebrate on which it feeds. In these circumstances, we can define three populations, that of the mosquitoes, that of the vertebrates and that of the disease. Each population is mobile and one (the disease) is a part of each of the other two. The inter-dependencies between the three populations are complex depending on many factors. These can again be split into (i) those internal to each population (e.g., density of vertebrates per unit area), (ii) those describing the relations between populations (e.g., proximity of vertebrates to vectors) and (iii) those external to the populations (e.g., proximity to water).

The effect of meteorological variables on vector populations and disease risk are less complex only in the sense that meteorological variables tend to vary spatially over larger distances than does land cover. Thus, for local studies, spatial variation in properties such as cold cloud duration (CCD) may be negligible. Rather, meteorological data are generally used to predict future vector densities and disease risk. For example, in a study by Hay et al. (1998a) monthly mean percentage of annual malaria admissions in The Gambia was found to be highly correlated with CCD lagged by two months. The implication is that if CCD is monitored it can be used to predict malaria risk two months in advance (see Chapter 9). Thus, whereas land cover data provide a wealth of spatial information, meteorological variables are more likely to provide temporal information on vector density or disease risk. This section reads much better than the first where the impression is that land cover is all important.

2.5.1 Predicting vector density or disease risk?

The researcher will need to be clear as to what primary variables are to be estimated and how these variables are to be organised.

\subsubsection{Choice of variables and predictive route}

Several researchers have sought to predict vector density or some other vector-related variable based on remotely sensed imagery. Others have sought to predict disease risk or some other disease-related variable directly from imagery. Clearly, if disease risk is predicted directly, the simple correlation obtained between the secondary (explanatory) variable(s) and the risk will depend on the vectors for which no information is available (Figure 1).

Some studies have involved prediction of vector density or disease risk based on the direct use of 
remotely sensed reflectance in several wavebands. Others have involved the processing of remotely sensed imagery into vegetation indices (such as the NDVI) or the classification of land cover type based on the imagery prior to prediction.

In this paper, we have so far implied and will now argue, that the most natural model is one in which, first, some land cover variable is predicted from remotely sensed imagery and second, this information on land cover is used to predict vector density or disease risk.

\subsubsection{Organising the primary variable}

Data on the primary phenomenon of interest, whether it be the vector or the disease, will generally be required to build a statistical model of its relation to the secondary variable (say, land cover type). These data may be acquired in a variety of formats. If the interest is in the vector, then the variable should be defined as a density, that is, number of vectors per unit area. The support (the size, geometry and orientation of the space on which each observation is defined) (Curran and Atkinson, 1999) should be constant across the region of interest. Thus, depending on the instrumentation and technique used to acquire data, the measured variable may need to be transformed prior to modelling. Where the secondary (explanatory) variable(s) are provided by remotely sensed imagery it may be advantageous to transform the primary vector variable to a grid with the same spatial resolution as the imagery. This step will facilitate the later co-location of the data within a GIS (Longley et al., 1999).

If the interest is disease risk, the primary data will often be in the form of number of patients admitted to a local clinic or hospital and diagnosed or treated for the disease. Ideally, data on location should be obtained for each individual so that the local spatial distribution of the disease can be mapped for each local medical centre. Then, the number of patients per unit area should be divided by the background population (ideally, the number of susceptibles) per unit area to produce an attack rate (or disease risk). As for the vector density, the disease risk can be produced on cells that match the pixels of remotely sensed imagery on which the predictive model will be constructed.

\subsubsection{Sampling issues}

\subsubsection{Choosing a spatial resolution}

A choice that the investigator will face early in any study involving remotely sensed imagery is that relating to spatial resolution. The many studies involving remote prediction of vectors or disease reviewed by Hay et al. 
(1997) can be divided into those involving fine spatial resolution and coarse spatial resolution imagery. Fine spatial resolution is used to refer to imagery such as that provided by SPOT HRV (10 m for panchromatic imagery), Landsat TM (30 m, in non-thermal wavelengths) and Landsat MSS (80 m). Coarse spatial resolution imagery is used to refer to imagery such as provided by the NOAA AVHRR $(1.1 \mathrm{~km}$ and $8 \mathrm{~km})$. Clearly, there is a large difference (2-3 orders of magnitude) between the two groups. The choice (in the first instance between the two groups) will depend on several factors. By far the most important criterion, however, is the spatial detail that needs to be resolved. Since the primary variable of interest can be defined as a density on any desired cell size (e.g., through interpolation) the choice of spatial resolution of imagery is a difficult one.

Important variables influencing the choice of spatial resolution include the spatial extent of the region of interest, the number of data that will be generated, the nature of the strategy intended to counter the disease (e.g., environmental measures) and the ability to (and utility of) targeting medical care spatially. In addition, the number of vertebrates carrying the disease and the number of susceptibles will decrease as the spatial resolution increases such that estimates of risk may become unreliable for small cell sizes. That is, very small cell sizes may be precluded on statistical grounds. We would suggest, however, that the most important criterion is the frequency of the spatial variation in the vector density (or disease risk). The spatial resolution should be chosen in relation to the scale(s) of spatial variation implicit in the variable of interest (Curran and Atkinson, 1999). The suggestion is that such scale(s) of variation should be quantified using a function such as the covariance function or variogram to aid in the choice of spatial resolution (Woodcock and Strahler, 1987; Atkinson and Curran, 1997).

\subsubsection{Spatial sampling of the primary variable}

Having chosen a spatial resolution (which can often mean a particular sensor), the next task will be to select a source of data on the primary variable of interest. Generally, the investigator will be limited to small numbers of data and usually archive sources (at least secondary sources). Nevertheless, it is worth considering here the effect of the sampling strategy on the resulting data. All data are a function of (i) the underlying property of interest and (ii) the sampling strategy. Therefore, the actual observed spatial variation will depend on the sampling strategy. Generally, systematic sampling is preferred over random sampling because it is more efficient where data are spatially dependent (proximate data pairs tend to be more similar than more distant data pairs) and this is usually the case (Atkinson, 1997). Whatever the circumstances, the investigator should strive to provide an even spatial coverage, at least of at-risk areas.

A second consideration relates to the support of the primary variable. This is likely to be approximated 
as a point in space and is unlikely to be the same as that of the remotely sensed imagery (land cover data). In practice, a variety of problems arise. Take the example of Hay et al. (1998a, 1998b) in which five local communities in Kenya were monitored for malaria infection. The data were referenced geographically as five points in space. Each datum, however, actually has a support that is much larger than a point. Further, the support is likely to have a bell-shaped centre weighting since more cases are likely to be reported by people living close to a medical centre than by people living further away. Ideally, the locations of individuals should be recorded allowing the estimation of cell-based averages as described above, although this is a very difficult undertaking.

If the data supports can be treated as points then the investigator has a choice. First, the point data could be used in modelling directly. The only consequence of this is that the model and the predictions will be less accurate than had the support been equal to the pixel. Second, the investigator could choose to interpolate to the support of the imagery (image pixels), for example, using block kriging (Atkinson, 1997). Any re-organisation of the data based on interpolation algorithms, however, will introduce the serious problem known as "smoothing". All linear weighted estimators involve smoothing. Smoothing means that the extent of the support of the estimates is larger than the desired support. In practice, smoothing alters the cumulative distribution function (cdf) of the estimated data set: specifically, the cdf of the estimated data has a smaller variance than that of the original data. This has serious implications where the objective is to build a model of the relation between the interpolated primary variable (i.e., vector density, disease risk) and the remotely sensed land cover and apply that model to predict the primary variable at other places or times.

A third consideration relates to the number of observations required. Where the statistical model of interest is regression (see below), this number can be small (say 30 observations that cover the region such that the full range of possible values is included). Where the model is classification-based (see below), this number can be uncomfortably large (say 30 observations per class, perhaps with more than ten classes).

2.5.3. Models for predicting vector density and disease risk

Many models are possible for predicting vector density and disease risk. Here we will comment on five such models.

\subsubsection{Temporal prediction: simple correlation on monthly averages}


As noted earlier in Section 2.5, Hay et al. (1998a) conducted research in which CCD lagged by two months was related to monthly percentage total of annual malaria admissions $\left(r^{2}=0.86\right)$. The CCD data were obtained from remotely sensed data of the Atlantic coast of The Gambia provided by NOAA AVHRR and Meteosat High Resolution Radiometer (HRR) imagery. As part of the same study the imagery were processed to estimate the NDVI and the relation to monthly percentage total of annual malaria admissions was found to be strong $r^{2}=0.66$. Since the remotely sensed NDVI provided a spatial distribution on a monthly basis, it was possible to extrapolate the prediction spatially to map areas at risk.

The fundamental problem with such a statistical approach based on temporal data is that relationships observed are not necessarily based on a physical link. It might be that the NDVI always peaks in July-August and that disease risk always peaks in October. If we know that disease risk always peaks in October then what use are the NDVI data? Equally, there might be no physical relationship between the dates of the two peaks. Multiple-year data are required to characterize the relation between the date and magnitude of peak NDVI and the date and magnitude of peak disease risk. Without this, the relations simply cannot be generalized to other years.

\subsubsection{Spatial prediction: hard land cover classes}

Where the remotely sensed imagery have been used to estimate hard land cover classes (e.g., using a supervised maximum likelihood classification, Section 2.4.1.2) the investigator needs to know how to use such information on land cover type to predict vector density or disease risk. A variety of approaches could be employed depending on several factors including how the primary variable is organized. For example, if the primary variable is treated as a binary indicator of presence or absence of the disease (e.g., below or above some critical threshold) then logistic regression (Webster and Oliver, 1990) could be used to predict from hard land cover classes (Section 2.4.2).

Treating the primary variable as continuous, the simplest method is to obtain data on risk for each land cover class and assign the means of the class-specific distributions to the classes. The distributions can be used to estimate the uncertainty associated with each mean and also, via a classical analysis of variance, to determine whether the differences between the means are significant (Webster and Oliver, 1990). Further, the distributions can be used to simulate different spatial realizations of vector density or disease risk.

An optimal, albeit more sophisticated, alternative would be to use the geostatistical technique known as kriging (Matheron, 1965; 1971). The term kriging refers to a set of generalised least-squares regression algorithms. All kriging algorithms are variants of the least squares regression estimator (Goovaerts, 1997): 


$$
\hat{Z}(\mathbf{V})-m(\mathbf{V})=\sum_{\alpha=1}^{n(\mathbf{V})} \lambda_{\alpha}(\mathbf{V})\left[Z\left(\mathbf{x}_{\alpha}\right)-m\left(\mathbf{x}_{\alpha}\right)\right]
$$

where $\lambda_{\alpha}$ are the weights applied to data $z\left(\mathbf{x}_{\alpha}\right)$ interpreted as realizations of the regionalised variable (RV) $\mathrm{Z}\left(\mathbf{x}_{\alpha}\right)$ and $m(\mathbf{V})$ and $m\left(\mathbf{x}_{\alpha}\right)$ are the means of the $\mathrm{RVs} \mathbf{Z}(\mathbf{V})$ and $\mathbf{Z}\left(\mathbf{x}_{\alpha}\right)$. In practice, prediction is achieved using only the $n(\mathbf{V})$ point or quasi-point data $z\left(\mathbf{x}_{\alpha}\right)$ at locations $\mathbf{x}_{\alpha}$ within a local neighbourhood $W(\mathbf{V})$.

The objective of all kriging estimators is to minimise the estimation variance under the constraint of unbiasedness. That is,

$$
\sigma_{E}^{2}(\mathbf{V})=\operatorname{var}\{\hat{Z}(\mathbf{V})-Z(\mathbf{V})\}
$$

is minimised under the constraint that

$$
\mathrm{E}\{\hat{Z}(\mathbf{V})-Z(\mathbf{V})\}=0
$$

The actual type of kriging estimator adopted varies depending on the model adopted for the random function (RF) and in particular, the model adopted for the mean. In general, the RF can be decomposed into two components as follows:

$$
Z(\mathbf{V})=R(\mathbf{V})+m(\mathbf{V})
$$

where $R(\mathbf{V})$ is modelled as having zero mean or expectation and its variation is modelled using the variogram. The component $m(\mathbf{V})$ is the mean of the $\mathrm{RF} Z(\mathbf{V})$ and this can be modelled in various ways depending on the type of kriging estimator adopted.

Where the secondary data are in the form of what is termed a categorical variable (that is, a "hard" land cover), they can be used directly as a model for the mean component. Kriging can then be applied to the residuals from that mean. This procedure is referred to as kriging with an external drift (Deutsch and Journel, 1992). Most often, the external drift is a two-dimensional polynomial (that is, trend surface), but it can equally be a categorical variable (Goovaerts, 1997; Pebesma and Wesseling, 1998). The main requirement for kriging in this form is sufficient data on the primary variable distributed spatially within the region of interest. This requirement can be difficult to meet in epidemiological studies however (Section 2.2). 
By first, classifying the land cover and, second, the vector density (or disease risk), the model follows more closely the physical processes occurring in reality (Figure 1). Thus, such a two-stage approach is recommended over a direct estimation of disease risk from remotely sensed imagery.

\subsubsection{Spatial prediction: soft land cover classes}

Traditional hard supervised classification (Section 2.4.1.2) while still popular in remote sensing is being replaced, albeit gradually, by the more informative soft or fuzzy classification. As described in Section 2.4.4, soft or fuzzy classification can be used to estimate the proportion of a given pixel belonging to each of the available classes. In these circumstances, the secondary data (of land cover proportion or probability) are a set of variables constrained in the interval 0-1. A range of approaches could be adopted to model the relation between these data and the vector density or disease risk (Webster and Oliver, 1990). None stand out as clearly the most appropriate, however.

One alternative would be to model the relation between vector density (or disease risk) and a hard class, and then estimate the mean per cell based on the fuzzy memberships (that is, estimate the mean as an average of each class, weighted by the proportion of the cell covered by each class. Kriging with an external drift could then be applied based on this spatially-varying estimate of the mean.

Another alternative would be to treat the secondary data as a set of continuous variables. The disadvantage of doing this is that the distribution of the data may need to be transformed prior to further analysis (e.g., using a logistic or arcsin transform) and that the fuzzy proportions will clearly be correlated between classes. If these problems are not serious, then cokriging (Myers, 1982; Atkinson et al., 1992; 1994) could be used to estimate the primary variable and successful application would once again (Section 2.5.3.2) depend on the availability of primary (e.g., vector or disease) data.

\subsubsection{Spatial prediction: vegetation amount}

In some cases it may be preferable to replace a land cover classification with a map of some quantitative land cover variable such as vegetation amount. In remote sensing, the estimation of vegetation-related variables has traditionally involved the use of multiple wavebands to calculate a vegetation index. The use of a vegetation index (e.g., NDVI) as a secondary variable has the advantage that multiple waveband information is compressed into a single variable. Further, indices such as the NDVI standardize for the amount of incoming radiation and information is provided as a continuous variable. Vegetation indices such as the NDVI, however, are highly correlated with properties such as leaf area index (LAI), and vector density or disease risk may be correlated 
with LAI, conditional upon specific climatic events (e.g., rains following drought). In these circumstances, an indirect link is established between the vegetation index and vector density or disease risk, such that the vegetation index may be used as a secondary variable for prediction. Since both the primary and secondary variables are continuous, the natural choice of statistical model for prediction is simple linear regression. Alternatively, where there are sufficient spatial data on the primary variable, kriging with an external drift or cokriging could be applied to make full use of the available spatial information.

Despite the apparent simplicity of this predictive route there are potential problems. First, the correlation will depend on climate, as mentioned above. Second, the correlation may vary geographically (e.g., mosquitoes may favour certain plants and proximity to water bodies). Thirdly, and most importantly there is no reason to expect a linear relation. Relations between the NDVI and vector density or disease risk, when they do occur, are likely to be non-linear, especially when one considers that the relation between the NDVI and LAI tends to be asymptotic. Such non-linear relations would need to be included in any model used for prediction.

\subsubsection{Spatial prediction: GIS variables}

Often, secondary information exists in a form where the primary variable is not a simple linear function of the secondary data expressed on a raster grid. For example, mosquito breeding depends on proximity to water bodies, proximity to vertebrates and so on. To obtain a simple linear relation, it is necessary to obtain a secondorder variable "proximity to water" as a function of the first-order variable "water". A GIS can be used to provide the new variable. For example, in the case of proximity to water, the new variable can be estimated by a GIS procedure known as "buffering" (Longley et al., 1999) applied to water bodies (themselves estimated through remote sensing and land cover classification). Care should be taken when deriving variables of this kind to ensure that the relations between the second-order variable and the primary variable of interest are linear. Then, the techniques described above (e.g., geostatistics) can be applied, treating the second-order information together with, say, land cover type.

\subsection{Discussion and conclusion}

The framework in Figure 1 has focussed our attention on the links between remotely sensed imagery and disease. In doing so it has highlighted the uncomfortable assumptions and gaps in understanding that have to be traversed if we are to use measures of radiation to predict vector density or better still disease risk. It is not unusual for scientific research to progress by observing and using relationships prior to understanding 
relationships (Curran, 1987). Such is the case in the use of remote sensing in epidemiology where, not surprisingly, early research concentrated on the development of correlations between images and disease and then the use of images to predict disease. It is clear, however, that progress will rest on the development of physical understanding (Sections 2.3 and 2.4) and the utilisation of optimised procedures for prediction (Section 2.5). Such progress is vital because

"despite the growing enthusiasm, disease prevention by satellite still has to prove itself for actual disease control" (M. Barinaga, 1993, p. 32).

Specifically, this paper makes four observations that will, it is hoped, help make remote sensing a vital component of the epidemiologists tool kit. 1. Land cover is central to the use of remote sensing in epidemiology. The accurate identification and quantification of land cover would be a useful part of prediction methodologies. 2. Remotely sensed data contain spectral, spatial and temporal information that can be used to characterise the Earth's surface. To exploit remotely sensed data to the full we must have a clear understanding of the scene, atmosphere, sensor and image and perhaps more importantly, links between them. 3. Many techniques are available for mapping land cover type from remotely sensed data. The most suitable techniques for epidemiological studies are likely to be soft classifications in which the proportion or probability of a class is attributed to each pixel. These will be derived from an approach to spectral unmixing or through the application of a soft or fuzzy image classifier. 4. The aim of predicting vector density and/or disease risk is hampered by a spatial and temporal mismatch between remotely sensed data and vector/disease data.

Optimal use of remote sensing will involve the optimisation of both spatial sampling and the models used for prediction in the context of the environment, the available data and the epidemiological problem. 


\section{References}

Adams, J.B., Sabol, D.E., Kapos, V., Filho, R.A., Roberts, D.A., Smith, M.O. and Gillespie, A.R. (1995). Classification of multispectral images based on fractions of endmembers: application to land-cover change in the Brazilian Amazon. Remote Sensing of Environment 52, 137-154.

Adams, J.B., Smith, M.O. and Gillespie, A.R., (1993). Imaging spectroscopy: interpretation based on spectral mixture analysis. In: Remote Geochemical Analysis: Elemental and Mineralogical Composition (C.M. Pieters and P.A.J. Englert, eds.), 145-166, Cambridge: Cambridge University Press.

Ahearn, S.C. and De Rooy, C. (1996). Monitoring the effects of Dracunculiasis remediation on agricultural productivity using satellite data. International Journal of Remote Sensing 5, 917-929.

Arora, M. K. and Foody, G. M. (1997). Log-linear modelling for the evaluation of the variables affecting the accuracy of probabilistic, fuzzy and neural network classifications. International Journal of Remote Sensing 18, $785-798$.

Atkinson, P.M. (1997). Scale and satial dependence. In: Scaling-up: From Cell to Landscape (P.R. van Gardingen, G.M.Foody and P.J. Curran, eds.), 35-60, Cambridge: Cambridge University Press.

Atkinson, P.M. and Curran, P.J. (1997). Choosing an appropriate spatial resolution for remote sensing investigations. Photogrammetric Engineering and Remote Sensing 63, 1345-1351.

Atkinson, P.M., Webster, R. and Curran, P.J. (1992). Cokriging with ground-based radiometry. Remote Sensing of Environment 41, 45-60.

Atkinson, P.M., Webster, R. and Curran, P.J. (1994). Cokriging with airborne MSS imagery. Remote Sensing of Environment 50, 335-345.

Bailey, C.L. and Linthicum, K.J. (1989). Satellite remote sensing: the newest technology for monitoring vector populations and predicting arbovirus outbreaks. Proceedings, 5th Symposium, Arbovirus Research in Australia. Brisbaine, Qld: CSIRO Division of Tropical Animal Production, 111-116.

Barinaga, M. (1993). Satellite data rocket disease control efforts into orbit. Science 261, 31-32.

Barrett, E. C. and Curtis, L. F. (1999). Introduction to Environmental Remote Sensing, fourth edition. Cheltenham: Stanley Thomas.

Bastin, L. (1997). Comparison of fuzzy c-means classification, linear mixture modelling and MLC probabilities as tools for unmixing coarse pixels. International Journal of Remote Sensing 18, 3629-3648.

Bauer, M. E., Burk, T. E., Ek, A. R., Coppin, P. R., Lime, S. D., Walsh, T. A. and Walters, D. K. (1994). Satellite inventory of Minnesota forest resources. Photogrammetric Engineering and Remote Sensing 60 , 287-298.

Beck, L.R., Rodriguez, M.H., Dister, S.W., Rodriguez, A.D., Rejmankova, E., Ulloa, A. Meza, R.A., Roberts, D.R., Paris, J.F., Spanner, M.A., Washino, R.K., Hacker, C. and Legters, L.J. (1994). Remote sensing as a landscape epidemiologic tool to identify villages at high risk for malaria transmission. American Journal of Tropical Medicine and Hygiene 5, 271-280.

Benediktsson, J. A. Swain, P. H. and Ersoy, O. K. (1990). Neural network approaches versus statistical methods in classification of multisource remote sensing data. IEEE Transactions on Geoscience and Remote Sensing 28, 540-551. 
Berberoglu, S., Lloyd, C.D., Atkinson, P.M. and Curran, P.J. (2000). The integration of spectral and textural information using neural networks for land cover mapping in the Mediterranean. Computers and Geosciences (in press).

Bishop, C. M. (1995). Neural Networks for Pattern Recognition. Oxford: Clarendon Press.

Boardman, J.W. (1994). Automating linear mixture analysis of imaging spectrometry data. In: Proceedings of the International Symposium on Spectral Sensing Research (R.B. Gomez ed.), US Army Corps of Engineers, Washington DC, 302-309.

Boyd, D.S. and Curran, P.J. (1998). Using remote sensing to reduce uncertainties in the global carbon budget: The potential of radiation acquired in midle infrared wavelengths. Remote Sensing Reviews 16, 293-327.

Campbell, J. B. (1996). Introduction to Remote Sensing, second edition. London: Taylor and Francis.

Cannon, R. L., Dave, J.V. Bezdek, J. C. and Trivedi, M. M. (1986). Segmentation of a thematic mapper image using the fuzzy c-means clustering algorithm. IEEE Transactions on Geoscience and Remote Sensing 24, 400-408.

Chavez, P.S. (1996). Image-based atmospheric corrections - revisited and improved. Photogrammetric Engineering and Remote Sensing 62, 1025-1036.

Cline, B.L. (1970). New eyes for epidemiologists: aerial photography and other remote sensing techniques. American Journal of Epidemiology 92, 85-89.

Cohen, J. (1960). A coefficient of agreement for nominal scales. Educational and Psychological Measurement 20, $37-46$.

Cohen, J. (1968). Weighted kappa. Psychological Bulletin 70, 213-220.

Colwell, J.E. (1974). Vegetation canopy reflectance. Remote Sensing of Environment 3, 175-183.

Congalton, R. G. (1991). A review of assessing the accuracy of classifications of remotely sensed data. Remote Sensing of Environment 37, 35-46.

Connor, S.J. (1999). Malaria in Africa: the view from space. Biologist 46, 22-25.

Cracknell, A.P. (1997) The Advanced Very High Resolution Radiometer (AVHRR). London: Taylor and Francis.

Crapper, P. F. (1984). An estimate of the number of boundary cells in a mapped landscape coded to grid cells. Photogrammetric Engineering and Remote Sensing 50, 1497-1503.

Crippen, R.E. (1988). The dangers of underestimating the importance of data adjustments in band ratioing. International Journal of Remote Sensing 9,767-776.

Crombie, M.K., Gilles, R.R., Arvidson, R.E., Brookmeyer, P., Weill, G.J., Sultan, M. and Harb, M. (1999). An application of remotely derived climatological fields for risk assessment of vector-borne disease: A spatial study of Filariasis prevalence in the Nile delta, Egypt. Photogrammetric Engineering and Remote Sensing 65, 1401-1409.

Cross, E. R., Newcomb, W. W. and Tucker, C. J. (1996). Use of weather data and remote sensing to predict the geographic and seasonal distribution of Phlebotomus papatasi in southwest Asia. American. Journal of Tropical Medicine and Hygiene 54, 530-536.

Curran, P.J. (1983). Multispectral remote sensing for the estimation of green leaf area index. Philosophical Transactions of the Royal Society, London, Series A 309, 257-270.

Curran, P.J. (1987). Remote sensing methodologies and geography. International Journal of Remote Sensing $\mathbf{8}$, 1255-1275.

Curran, P.J. (1989). Remote sensing of foliar chemistry. Remote Sensing of Environment 30, 271-277. 
Curran, P.J. (1994). Imaging spectrometry. Progress in Physical Geography 18, 247-266.

Curran, P.J. and Atkinson, P.M. (1999). Issues of scale and optimal pixel size. In: Spatial Statistics in Remote Sensing (A. Stein and F. van der Meer, eds), 115-133, Dordrecht: Kluwer.

Curran, P. J. and Williamson, H. D. (1985). The accuracy of ground data used in remote sensing investigations. International Journal of Remote Sensing 6, 1637-1651.

Curran, P.J., Kupiec, J.A. and Smith, G.M. (1997). Remote sensing the biochemical composition of a slash pine canopy. IEEE Transactions on Geoscience and Remote Sensing 35, 415-420.

Curran, P.J., Milton, E.J., Atkinson, P.M. and Foody. G.M. (1998). Remote sensing from data to understanding. In: Geocomputation: A Primer (P. Longley, S. Brooks, W. Macmillan and R. McDonnell eds), 33-59, Chichester: Wiley \& Sons.

Danson, F.M., Craig, P.S. and Man, W. (2000). Land use changes and disease transmission in central China. In : Tapeworm Zoonoses - An Emergent Global Problem, NATO Science Series, Amsterdam: IOS Press (in press).

Deutsch, C.V. and Journel, A.G. (1992). GSLIB Geostatistical Software Library. Oxford: Oxford University Press.

Estrada-Peña, A. (1998). Geostatistics and remote sensing in predictive tools of tick distribution: A cokriging system to estimate Ixodes scapularis (Acari: Ixodidae) habitat suitability in the United States and Canada from advanced very high resolution radiometer data. Journal of Entomology 35, 989-995.

Fischer, M. M., Gopal, S., Staufer, P. and Steinnocher, K. (1997). Evaluation of neural pattern classifiers for a remote sensing application. Geographical Systems 4, 195-225.

Foody, G. M. (1991). Soil moisture content ground data for remote sensing investigations of agricultural regions. International Journal of Remote Sensing 12, 1461-1469.

Foody, G. M. (1992). On the compensation for chance agreement in image classification accuracy assessment. Photogrammetric Engineering and Remote Sensing 58, 1459-1460.

Foody, G. M. (1996). Approaches for the production and evaluation of fuzzy land cover classifications from remotely sensed data. International Journal of Remote Sensing 17, 1317-1340.

Foody, G. M. (1997). Fully fuzzy supervised classification of land cover from remotely sensed imagery with an artificial neural network. Neural Computing and Applications 5, 238-247.

Foody, G. M. (1999). The continuum of classification fuzziness in thematic mapping. Photogrammetric Engineering and Remote Sensing 65, 443-451.

Foody, G. M. and Arora, M. K. (1996). Incorporating mixed pixels in the training, allocation and testing stages of supervised classifications. Pattern Recognition Letters 17, 1389-1398.

Foody, G. M. and Arora, M. K. (1997). An evaluation of some factors affecting the accuracy of classification by an artificial neural network. International Journal of Remote Sensing 18, 799-810.

Foody, G.M. and Curran, P.J. (1994). Estimation of tropical forest extent and regenerative stage using remotely sensed data. Journal of Biogeography 21, 223-244.

Foody, G. M., Campbell, N. A. Trodd, N. M. and Wood, T. F. (1992). Derivation and applications of probabilistic measures of class membership from the maximum likelihood classification. Photogrammetric Engineering and Remote Sensing 58, 1335-1341. 
Foody, G. M., Palubinskas, G, Lucas, R. M., Curran, P. J. and Honzak, M. (1996). Identifying terrestrial carbon sinks: classification of successional stages in regenerating tropical forest from Landsat TM data. Remote Sensing of Environment 55, 205-216.

Gitelson, A.A., Kaufman, Y.J. and Merzlyak, M.N. (1996). Use of a green channel in remote sensing of global vegetation from EOS-MODIS. Remote Sensing of Environment 58, 289-298.

Goel, N.S. (1988). Models of Vegetation Canopy Reflectance and their use in Estimation of Biophysical Parameters. London: Harwood Academic Publishers.

Goetz, A.F.H., Rowan, L.C. and Kingston, M.J. (1982). Mineral identification from orbit: initial results from the Shuttle Multispectral Infrared Radiometer. Science 218, 1020-1024.

Goovaerts, P. (1997). Geostatistics for Natural Resources Evaluation. Oxford: Oxford University Press.

Gopal, S. and Woodcock, C. (1994). Theory and methods for accuracy assessment of thematic maps using fuzzy sets. Photogrammetric Engineering and Remote Sensing 60,181-188.

Groom, G.B., Fuller, R.M. and Jones, A.R. (1996). Contextual correction: Techniques for improving land cover mapping from remotely sensed images. International Journal of Remote Sensing 17, 69-89.

Gurney, C.M. and Townshend, J.R.G. (1983). The use of contextual information in the classification of remotely sensed data. Photogrammetric Engineering and Remote Sensing 49, 55-64.

Guyot, G. and Gu, X. F. (1994). Effect of radiometric corrections on NDVI determined from SPOT HRV and Landsat TM. Remote Sensing of Environment 49, 169-180.

Haralick, R.M. and Shanmugam, K. S. (1974). Combined spectral and spatial processing of ERTS imagery data. Remote Sensing of Environment 3, 3-13.

Harris, R. (1985). Contextual classification processing of Landsat data using a probabilistic relaxation model. International Journal of Remote Sensing 6, 847-866.

Hay, S.I. (2000). An overview of remote sensing and geodesy for public health applications. Advances in Parasitology (in press).

Hay, S. I., Packer, M. J. and Rogers, D. J. (1997). The impact of remote sensing on the study and control of invertebrate intermediate hosts and vectors for disease. International Journal of Remote Sensing 18, 28992930.

Hay, S.I., Snow, R.W. and Rogers, D.J. (1998a). Predicting malaria seasons in Kenya using multitemporal meteorological satellite sensor data. Transactions of the Royal Society of Tropical Medicine and Hygiene 92, 12-20.

Hay, S.I., Snow, R.W. and Rogers, D.J. (1998b). From predicting mosquito habitat to malaria seasons using remotely sensed data: practices, problems and perspectives. Parasitology Today 14, 306-313.

Hay, S.I., Tucker, C.J., Rogers, D.J. and Packer, M.J. (1996). Remotely sensed surrogates of meteorological data for the study of the distribution and abundance of arthropod vectors of disease. Annals of Tropical Medicine and Parasitology 90, 1-19.

Hayes, R. O., Maxwell, E. L., Mitchell, C. J. and Woodzick, T. L. (1985). Detection, identification, and classification of mosquito larval habitats using remote sensing scanners in earth-orbiting satellites. Bulletin of the World Health Organisation 63, 361-374.

Holmes, Q. A., Nuesch, D. R. and Shuchman, R. A. (1984). Textural analysis and real-time classification of seaice types using digital SAR data. IEEE Transactions on Geoscience and Remote Sensing 22, 113-120. 
Horsfall, W.R. (1955). Mosquitos: Their Bionomics and Relation to Disease. New York: Ronald Press.

Hugh-Jones, M. (1989). Applications of remote sensing to the identification of the habitats of parasites and disease vectors. Parasitology Today 5, 244-251.

Hugh-Jones, M. (1991a). The remote recognition of tick habitats. Journal of Agricultural Entomology 8, 309315.

Hugh-Jones, M. (1991b). Satellite imaging as a technique for obtaining disease-related data. Review Scientifique et Technique de l'Office International Epizooties 10, 197-204.

Hugh-Jones, M. and O'Neil, P. (1986). The epidemiological uses of remote sensing and satellites. Proceedings of the Fourth International Symposium on Veterinary Epidemiology, Singapore: Singapore Veterinary Association, 113-118.

Hugh-Jones, M.E., Barre, N., Nelson, G., Wheyness, C., Warner, J., Garris, G. and Hubbert, W. (1988). Remote recognition of Amblyomma variegatum habitats in Guadeloupe using Landsat-TM imagery. Acta Veteriinaria Scandinavia 84, 259-261.

Hutchinson, C. F. (1982).Techniques for combining Landsat and ancillary data for digital classification improvement. Photogrammetric Engineering and Remote Sensing 48, 123-130.

Innes, J.L. and Koch, B. (1998). Forest biodiversity and its assessment by remote sensing. Global Ecology and Biogeography Letters 7, 397-419.

Irons, J.R., Campbell, G.S., Norman, J.M., Graham, D.W. and Kovalick, W.M. (1992). Prediction and measurement of soil bidirectional reflectance. IEEE Transactions on Geoscience and Remote Sensing 30, 249-260.

Jensen, J.R. (1996). Introductory Digital Image Processing, second edition. New Jersey: Prentice Hall.

Justice, C.O., Townshend, J.R.G., Holben, B.N. and Tucker, C.J. (1985). Analysis of the phenology of global vegetation using meteorological satellite data. International Journal of Remote Sensing 6, 1271-1318.

Kelly, M., Estes, J. E. and Knight, K. A. (1999). Image interpretation keys for validation of global land-cover data sets. Photogrammetric Engineering and Remote Sensing 65, 1041-1049.

Kieffer, H.H. and Wildey, R.L. (1985). Absolute calibration of Landsat instruments using the moon. Photogrammetric Engineering and Remote Sensing 51, 1391-1393.

Kleiner, K. (1995). Satellites wage war on disease. New Scientist. 9 December, 9.

Kriebel, K.T. (1976). On the variability of the reflected radiation field due to differing distributions of the irradiation. Remote Sensing of Environment 4, 257-264.

Legters, L. J. (1994). Remote sensing as a landscape epidemiologic tool to identify villages at risk for malaria transmission. American Journal of Tropical Medicine and Hygiene 51, 271-280.

Lillesand, T. M. and Kiefer, R. W. (1999). Remote Sensing and Image Interpretation, fourth edition. New York: Wiley \& Sons.

Linthicum, K.J., Anyamba, A., Tucker, C.J., Kelley, P.W., Myers, M.F. and Peters, C.J. (1999). Climate and satellite indicators to forecast rift valley fever epidemics in Kenya. Science 285, 397-400.

Linthicum, K.J., Bailey, C.L., Glyn Davies, F. and Tucker, C.J. (1987). Detection of rift valley fever viral activity in Kenya by satellite remote sensing imagery. Science 235, 1656-1659. 
Lloyd, C.D., Berberoglu S., Curran, P.J. and Atkinson, P.M. (2000). The use of geostatistical structure functions and the co-occurance matrix for per-field land cover mapping in the Mediterranean. Remote Sensing of Environment (in press).

Longley, P., Goodchild, M., Maguire, D and Rhind, D. eds. (1999). Geographical Information Systems: Principles, Techniques, Management and Applications. New York: Wiley \& Sons.

Mackay, G., Steven, M.D. and Clark, J.A. (1998). An atmospheric correction procedure for the ATSR-2 visible and near-infrared land surface data. International Journal of Remote Sensing 19, 2949-2968.

Malone, J.B., Huh, O.K., Abdel-Rahman, M.S., El Bahy, M.M., Huh, O.K., Shafik, M. and Bava, M. (1997). Geographic information systems and the distribution of Shistosoma manosoni in the Nile delta. Parasitology Today 13, 112-119.

Maselli, F., Conese, C. and Petkov, L. (1994). Use of probability entropy for the estimation and graphical representation of the accuracy of maximum likelihood classifications. ISPRS Journal of Photogrammetry and Remote Sensing 49, 13-20.

Mather, P.M. (1999a). Computer Processing of Remotely-Sensed Images: An Introduction, second edition. Chichester: Wiley \& Sons.

Mather, P. M. (1999b). Land cover classification revisited. In: Advances in Remote Sensing and GIS Analysis. (P. M. Atkinson and N. J. Tate, eds). pp. 7-16. Chichester: Wiley \& Sons.

Matheron, G. (1965). Les Variables Régionalisées et Leur Estimation. Paris: Masson.

Matheron, G. (1971). The Theory of Regionalized Variables and its Applications. Fontainbleau: Centre de Morphologies Mathématique de Fontainbleau.

Milton, E.J. (1987). Principles of field spectroscopy. International Journal of Remote Sensing 8, 1807-1827.

Milton, E.J. (1999). Image endmembers and the scene model. Canadian Journal of Remote Sensing 25, 112120.

Miranda, F. P. and Carr, J. R. (1994). Application of the semivariogram textural classifier (STC) for vegetation discrimination using SIR-B data on the Guiana Shield, northwestern Brazil. Remote Sensing Reviews 10, $155-168$.

Myers, D.E. (1982). Matrix formulation of cokriging. Mathematical Geology 14, 249-250.

Nicodemus, F.F., Richmond, J.C., Hsia, J.J., Ginsberg, I.W. and Limperis, T.L. (1977). Geometrical Considerations and Nomenclature for Reflectance. National Bureau of Standards Monograph 160. Washington D.C: U.S. Government Printing Office.

Paola, J. D. and Schowengerdt, R. A. (1995). A detailed comparison of backpropagation neural network and maximum likelihood classification for urban land use classification. IEEE Transactions on Geoscience and Remote Sensing 33, 981-996.

Pavlovsky, E. (1966). Natural Nidality of Transmissible Diseases with Special Reference to the Landscape Epidemiology of Zooanthroponoses (Translated by F. Plous Jr; N. Levine ed.). Urbana, London: University of Illinois Press.

Pebesma, E.J. and Wesseling, C.G. (1998) GSTAT - a program for geostatistical modelling, prediction and simulation. Computers and Geosciences 24, 17-31. 
Peddle, D. R. (1993). An empirical comparison of evidential reasoning, linear discriminant analysis, and maximum likelihood algorithms for alpine land cover classification. Canadian Journal of Remote Sensing 19, 31-44.

Peddle, D. R., Foody, G. M., Zhang, A., Franklin, S. E. and LeDrew, E. F. (1994). Multisource image classification II: an empirical comparison of evidential reasoning and neural network approaches. Canadian Journal of Remote Sensing 20, 397-408.

Philipson, W.R. ed. (1997) Manual of Photographic Interpretation, second edition. Bethesda MD: American Society for Photogrammetry and Remote Sensing.

Pope, K. O., Rejmankova, E., Savage, H. M., Arrendondo-Jimenez, J. I, Rodriguez, M. H. and Roberts, D. R. (1994). Remote sensing of tropical wetlands for malaria control in Chiapas, Mexico. Ecological Applications 4, 81-90.

Pope, K.O., Sheffner, E.J., Linthicum, K.J., Bailey, C.L. and Logan, T.M., Kasischke, E.S., Birney, K., Njogu, A.R. and Roberts, C.R. (1992). Identification of central Kenyan rift valley fever virus vector habitats with Landsat TM and evaluation of their flooding status with airborne imaging radar. Remote Sensing of Environment 40, 185-196.

Price, J. C. (1987). Calibration of satellite radiometers and the comparison of vegetation indices. Remote Sensing of Environment 21, 15-27.

Price, J.C. (1990). On the information content of soil reflectance spectra. Remote Sensing of Environment 33, $113-121$.

Rees, G. (1999). The Remote Sensing Data Book. Cambridge: Cambridge University Press.

Rejmankova, E., Roberts, D. R., Pawley, A., Manguin, S. and Polanco, J. (1995). Predictions of adult Anopheles albimanus densities in villages based on distances to remotely sensed larval habitats. American. Journal of Tropical Medicine and Hygiene 53, 482-488.

Richards, J.A. (1993). Remote Sensing Digital Image Analysis: An Introduction, second edition. Berlin: Springer Verlag.

Riley, J. R. (1989). Remote sensing in entomology, Annual Review of Entomology 34, 247-271.

Roberts, D., Rodriguez, M., Rejmankova, E., Pope, K., Savage, H., Rodriguez-Ramirez, A., Wood, B., Salute, J. and Legters, L. (1991). Overview of field studies for the application of remote sensing to the study of malaria transmission in Tapachula, Mexico. Preventive Veterinary Medicine 11, 269-275.

Roberts, D.A., Gardner, M., Church, R., Ustin, S., Scheer, G. and Green, R.O. (1998). Mapping chaparal in the Santa Monica Mountains using multiple endmember spectral mixture models. Remote Sensing of Environment 65, 267-279.

Roberts, D.R., Paris, J.F., Manguin, S., Harbach, R.E., Woodruff, R., Rejmankova, E., Polanco, J., Wullschleger, B. and Legters, L. J. (1996). Predictions of malaria vector distribution in Belize based on multispectral satellite data. American Journal of Tropical Medicine and Hygiene 54, 304-308.

Robinson, T., Rogers, D. and Williams, B. (1997). Univariate analysis of tsetse habitat in the common fly belt of Southern Africa using climate and remotely sensed vegetation data. Medical and Veterinary Entomology 11, 223-234.

Rogers, D.J. and Randolph, S.E. (1991). Mortality rates and population density of tsetse filies correlated with satellite imagery. Nature 351, 739-741. 
Rogers, D.J. and Randolph, S.E. (1993). Distribution of tsetse and ticks in Africa: past, present and future. Parasitology Today 9, 266-271.

Rogers, D.J. and Williams, B.G. (1993). Monitoring trypanosomiasis in space and time. Parasitology 106, 77 92.

Rogers, D.J., Hay, S.I. and Packer, M.J. (1996). Predicting the distribution of tsetse flies in West Africa using temporal Fourier processed meteorological satellite data. Annals of Tropical Medicine and Parasitology 90 , 225-241.

Rosenfield, G. H. and Fitzpatrick-Lins, K. (1986). A coefficient of agreement as a measure of thematic classification accuracy. Photogrammetric Engineering and Remote Sensing 52, 223-227.

Roughgarden, J., Running, S.W. and Matson, P.A. (1991). What does remote sensing do for ecology? Ecology 72, 1918-1922.

Schalkoff, R. J. (1992). Pattern Recognition. Statistical Structural and Neural Approaches. New York: Wiley \& Sons.

Schowengerdt, R.A. (1997). Remote Sensing Models and Methods for Image Processing, second edition. San Diego: Academic Press.

Sellers, P.J. (1987). Canopy reflectance, photosynthesis, and transpiration. II. The role of biophysics in the linearity of their interdependence. Remote Sensing of Environment 21, 143-183.

Slater, P.N. (1984). The importance and attainment of accurate absolute radiometric calibration. Proceedings of SPIE - The International Society for Optical Engineering, SPIE, 475, 34-40.

Srinivasan, A. and Richards, J. A. (1990). Knowledge-based techniques for multi-source classification. International Journal of Remote Sensing 11, 505-525.

Stehman, S.V. and Czaplewski, R.L. (1998). Design and analysis for thematic map accuracy assessment: fundamental principles. Remote Sensing of Environment 64, 331-344.

Steven, M. D. (1987). Ground truth-an underview. International Journal of Remote Sensing 8, 1033-1038.

Story, M. and Congalton, R. G. (1986). Accuracy assessment: a user's perspective. Photogrammetric Engineering and Remote Sensing 52, 397-399.

Strahler, A. H. (1980). The use of prior probabilities in maximum likelihood classification of remotely sensed data. Remote Sensing of Environment 10, 135-163.

Strahler, A.H., Woodcock, C.E. and Smith, J.A. (1986). On the nature of models in remote sensing. Remote Sensing of Environment 20, 121-139.

Tanré, D., Deroo, C., Duhaut, P., Perbos, J. and Deschamps, P.Y. (1990). Description of a computer code to simulate the satellite signal in the solar spectrum : the 5S code. International Journal of Remote Sensing 11, 659-668.

Teillet, P.M., Slater, P.M., Ding, Y., Santor, R.P., Jackson, R.D. and Moran, M.S. (1990). Three methods for the absolute calibration of the NOAA AVHRR sensors in-flight. Remote Sensing of Environment 31, 105-120.

Thomson, M. C., Connor, S. J., D’Alessandro, U., Rowlingson, B., Diggle, P., Cresswell, M. and Greenwood, B. (1999). Predicting malaria infection in Gambian children from satellite data and bed net use surveys: the importance of spatial correlation in the interpretation of results. American. Journal of Tropical Medicine and Hygiene 61, 2-8. 
Thomson, M.C., Connor, S.J., Milligan, P.J.M. and Flasse, S.P. (1996). The ecology of malaria - as seen from Earth-observation satellites. Annals of Tropical Medicine and Parasitology 90, 243-264.

Townshend, J. R. G. (1992). Land cover. International Journal of Remote Sensing 13, 1319-1328.

Verstraete, M.M. and Pinty, B. (1996). Designing optimal spectral indexes for remote sensing applications. IEEE Transactions on Geoscience and Remote Sensing 34, 1254-1265.

Verstraete, M.M., Pinty, B. and Curran, P.J. (1999). MERIS potential for land applications. International Journal of Remote Sensing 20, 1747-1756.

Wang, F. (1990). Fuzzy supervised classification of remote sensing images. IEEE Transactions on Geoscience and Remote Sensing 28, 194-201.

Washino, R.K. and Wood, B.L. (1994). Application of remote sensing to arthropod vector surveillance and control. American Journal of Tropical Medicine and Hygeine 50, 134-144.

Webster, R. and Oliver, M.A. (1990). Statistical Methods for Soil and Land Resources Survey. Oxford: Oxford University Press.

Welch, J.B., Olson, J.K., Hart, W.G., Ingle, S.G. and Davis, M.R. (1989a). Use of aerial color infrared photography as a survey technique for Psorophora columbiae oviposition habitats in Texas ricelands. Journal of the American Mosquito Control Association 5, 147-160.

Welch, J.B., Olson, J.K., Yates, M.M., Benton Jr., A.R. and Baker, R.D. (1989b). Conceptual model for the use of aerial color infrared photography by mosquito control districts as a survey technique for Psorophora columbiae oviposition habitats in Texas ricelands. Journal of the American Mosquito Control Association 5 , 369-373.

Wilkinson, G. G. (1996). Classification algorithms - where next?. In: Soft Computing in Remote Sensing Data Analysis (E. Binaghi, P. A. Brivio and A. Rampini, eds), 93-99, Singapore: World Scientific.

Wood, B.L., Beck, L.R., Washino, R.K., Hibbard, K.A. and Salute, J.S. (1992). Estimating high mosquitoproducing rice fields using spectral and spatial data. International Journal of Remote Sensing 13, 28132826.

Wood, B.L., Washino, R., Beck, L., Hibbard, K.A., Pitcairn, M., Roberts, D., Rejmankova, E., Paris, J., Hacker, C., Salute, J., Sebesta, P. and Legters, L. (1991). Distinguishing high and low anopheline-producing rice fields using remote sensing and GIS technologies. Preventive Veterinary Medicine 11, 277-288.

Woodcock, C.E., and Strahler, A.H. (1987). The factor of scale in remote sensing. Remote Sensing of Environment 21, 311-322. 


\section{List of Tables}

Table $1 \quad$ Four illustrative examples of the framework in figure 1.

Table 2 A selection of papers from 1988 to 1999 to illustrate the range of remotely sensed imagery, characterisation of land cover and spatial units involved in the remote sensing of disease. Definitions of the remote sensing abbreviations are given in the text. 
Table 1 Four illustrative examples of the framework in Figure 1.

\begin{tabular}{|c|c|c|c|c|}
\hline & Example one & Example two & Example three & Example four \\
\hline IMAGE(S) & $\begin{array}{l}\text { Landsat TM coverage of a } \\
\text { region for a given day, last } \\
\text { month }\end{array}$ & $\begin{array}{l}\text { NOAA AVHRR coverage of a } \\
\text { country, maximum NDVI } \\
\text { values from last month }\end{array}$ & $\begin{array}{l}\text { JERS-1 SAR coverage of a } \\
\text { country for summer and winter } \\
\text { last year }\end{array}$ & $\begin{array}{l}\text { Landsat MSS coverage of an } \\
\text { agricultural region, ten years } \\
\text { ago }\end{array}$ \\
\hline RADIATION & $\begin{array}{l}\text { Six wavebands (visible to } \\
\text { middle infrared) for } 30 \mathrm{~m} \times 30 \mathrm{~m} \\
\text { area for a given day, last month }\end{array}$ & $\begin{array}{l}\text { Two wavebands (visible and } \\
\text { near infrared) for } 1.1 \mathrm{~km} \mathrm{x} \\
1.1 \mathrm{~km} \text { area for various times } \\
\text { last month }\end{array}$ & $\begin{array}{l}\text { Backscattered microwaves for } \\
18 \mathrm{~m} \times 18 \mathrm{~m} \text { areas for two dates, } \\
\text { last year }\end{array}$ & $\begin{array}{l}\text { Four wavebands (visible to } \\
\text { near infrared) for } 80 \mathrm{~m} \times 80 \mathrm{~m} \\
\text { areas, ten years ago }\end{array}$ \\
\hline LAND COVER & $\begin{array}{l}\text { Mix of water, pasture and } \\
\text { villages for a region, last month }\end{array}$ & $\begin{array}{l}\text { Amount of green biomass for a } \\
\text { country, last month }\end{array}$ & $\begin{array}{l}\text { Deciduous forest for a country, } \\
\text { last year }\end{array}$ & $\begin{array}{l}\text { Proportion of land cover that is } \\
\text { open scrub within } 5 \mathrm{~km} \text { of any } \\
\text { village, ten years ago }\end{array}$ \\
\hline VECTOR & Point data on mosquitoes, now & $\begin{array}{l}\text { Point data on tsetse flies, last } \\
\text { month }\end{array}$ & $\begin{array}{l}\text { Point data on ticks in spring of } \\
\text { this year }\end{array}$ & $\begin{array}{l}\text { Point observations of vole } \\
\text { presence, ten years ago }\end{array}$ \\
\hline DISEASE & $\begin{array}{l}\text { Point data on malaria, next } \\
\text { month }\end{array}$ & $\begin{array}{l}\text { Point data on sleeping sickness, } \\
\text { today }\end{array}$ & $\begin{array}{l}\text { Point data on Lyme disease in } \\
\text { summer of this year }\end{array}$ & $\begin{array}{l}\text { Point data on liver disease, } \\
\text { today }\end{array}$ \\
\hline
\end{tabular}


Table 2 A selection of papers from 1988 to 1999 to illustrate the range of remotely sensed imagery, characterisation of land cover and spatial units involved in the remote sensing of disease. Definitions of the remote sensing abbreviations are provided in the text.

\begin{tabular}{|c|c|c|c|c|c|c|}
\hline Reference & Location(s) & $\begin{array}{l}\text { Remotely sensed } \\
\text { data to study land }\end{array}$ & $\begin{array}{l}\text { Remotely sensed } \\
\text { spatial sampling } \\
\text { unit }\end{array}$ & Land cover & Disease/vector & $\begin{array}{l}\text { Disease/vector spatial } \\
\text { sampling unit }\end{array}$ \\
\hline $\begin{array}{l}\text { Hugh-Jones et al. } \\
\text { (1988) }\end{array}$ & Guadeloupe & Landsat TM & $30 \mathrm{~m}$ & Land cover & African bont tick & 967 cattle \\
\hline Welch et al. (1989a) & Texas USA & $\begin{array}{l}\text { Colour infrared } \\
\text { aerial photography }\end{array}$ & Various & $\begin{array}{l}\text { Land and water } \\
\text { cover }\end{array}$ & Mosquito & $286 \times 10^{3}$ acres \\
\hline $\begin{array}{l}\text { Welch et al. } \\
(1989 \mathrm{~b})\end{array}$ & Texas USA & $\begin{array}{l}\text { Colour infrared } \\
\text { aerial photography }\end{array}$ & Various & $\begin{array}{l}\text { Land and water } \\
\text { cover }\end{array}$ & Mosquito & $232 \mathrm{~cm}^{2}$ \\
\hline Wood et al. (1991) & California USA & $\begin{array}{l}\text { TM Simulator/ } \\
\text { Landsat TM }\end{array}$ & $? / 30 \mathrm{~m}$ & $\begin{array}{l}\text { Water and } \\
\text { vegetation cover }\end{array}$ & Mosquito lavae & $104 \times 2000 \mathrm{~m}^{2}$ fields \\
\hline $\begin{array}{l}\text { Rogers and Randolf } \\
\text { (1991) }\end{array}$ & $\begin{array}{l}\text { West Africa (Côte } \\
\text { d'Ivoire, Burkina } \\
\text { Faso) }\end{array}$ & AVHRR NDVI & $1.1 \mathrm{~km}$ & Vegetation amount & $\begin{array}{l}\text { Trypanosomiasis/ } \\
\text { Tsetse }\end{array}$ & $700 \mathrm{~km}$ long transect \\
\hline Pope et al. (1992) & Kenya & $\begin{array}{l}\text { Airborne SAR/ } \\
\text { Landsat TM } \\
\text { (classify) }\end{array}$ & $2.4 \mathrm{~m} / 30 \mathrm{~m}$ & Topography & $\begin{array}{l}\text { Rift valley fever } \\
\text { virus/Mosquito }\end{array}$ & Dambos in river valleys \\
\hline Wood et al. (1992) & California USA & $\begin{array}{l}\text { TM Simulator } \\
\text { (mean NDVI) }\end{array}$ & $?$ & $\begin{array}{l}\text { Water and } \\
\text { vegetation cover }\end{array}$ & Mosquito lavae & $104 / 2000 \mathrm{~m}^{2}$ fields \\
\hline $\begin{array}{l}\text { Rogers and Randolf } \\
\text { (1993) }\end{array}$ & $\begin{array}{l}\text { Zimbabwe } \\
\text { Kenya } \\
\text { Tanzania } \\
\end{array}$ & AVHRR NDVI & $1.1 \mathrm{~km}$ & Vegetation amount & $\begin{array}{l}\text { Trypanosomiasis/ } \\
\text { Tsetse } \\
\text { Ticks }\end{array}$ & $?$ \\
\hline Beck et al. (1994) & Mexico & Landsat TM & $30 \mathrm{~m}$ & Land cover & Malaria/Mosquito & $\begin{array}{l}\text { Landscape around } 40 \\
\text { villages }\end{array}$ \\
\hline $\begin{array}{l}\text { Ahearn and DeRooy } \\
(1996)\end{array}$ & Kwara State Nigeria & Landsat TM & $30 \mathrm{~m}$ & Vegetation amount & $\begin{array}{l}\text { Guinea worm/Water } \\
\text { flea }\end{array}$ & $?$ \\
\hline $\begin{array}{l}\text { Roberts et al. } \\
(1996)\end{array}$ & Belize & SPOT HRV & $20 \mathrm{~m}$ & Vegetation amount & Malaria/Mosquito & $\begin{array}{l}4 \text { legs at } 20 \text { sample points } \\
\text { along highway }\end{array}$ \\
\hline Rogers et al. (1996) & $\begin{array}{l}\text { Côte d'Ivoire and } \\
\text { Burkina Faso }\end{array}$ & $\begin{array}{l}\text { AVHRR NDVI, } \\
\text { temp }\end{array}$ & $7.6 \mathrm{~km}$ & Vegetation amount & $\begin{array}{l}\text { Trypanosomiasis/ } \\
\text { Tsetse }\end{array}$ & $0.250^{\circ}$ \\
\hline $\begin{array}{l}\text { Robinson et al. } \\
\text { (1997) }\end{array}$ & $\begin{array}{l}\text { Malawi } \\
\text { Mozambique } \\
\text { Zambia } \\
\text { Zimbabwe } \\
\end{array}$ & AVHRR NDVI & $1.1 \mathrm{~km}$ & Vegetation amount & $\begin{array}{l}\text { Trypanosomiasis/ } \\
\text { Tsetse }\end{array}$ & 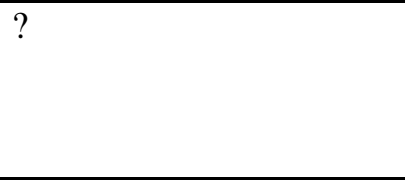 \\
\hline Hay et al. (1998) & Kenya & $\begin{array}{l}\text { AVHRR NDVI, } \\
\text { temp, MIR }\end{array}$ & $8 \mathrm{~km}$ & Vegetation amount & Malaria/Mosquito & $\begin{array}{l}\text { Catchment of hospitals in } \\
3 \text { villages }\end{array}$ \\
\hline $\begin{array}{l}\text { Thomson et } \\
\text { al.(1999) }\end{array}$ & Gambia & AVHRR NDVI & $1.1 \mathrm{~km}$ & Vegetation amount & Malaria/Mosquito & $\begin{array}{l}2039 \text { children from } 65 \\
\text { villages }\end{array}$ \\
\hline
\end{tabular}




\section{List of Figures}

Figure 1. A framework linking remotely sensed images with disease. Note that land cover refers to both type (e.g., forest, grass) and amount (e.g., high biomass, low biomass).

Figure 2. The remote sensing information system (discussion in text).

Figure 3. The geometric variables associated with remote sensing measurements (adapted from: Kriebel et al., 1976).

Figure 4. Classification accuracy assessment with a confusion or error matrix. The matrix is a cross-tabulation of the class label derived from the classification and the corresponding actual class label for a set of testing pixels. The ground data providing the actual class labels may, like any data set, contain uncertainties and error. Indeed many factors influence the quality of the ground data used in remote sensing investigations and the data are unlikely to be error-free (Curran and Williamson, 1985; Steven, 1987; Foody, 1991; Bauer et al., 1994). The accuracy assessment is, therefore, in reality a measure of the degree of agreement or correspondence between the labels derived from the classification and those depicted in the ground data. The quality of the ground data set is, therefore, critical and must be considered when deriving a classification accuracy statement. Once formed, however, a range of measures to indicate the accuracy of the classification may be derived. The matrix shown is taken from a study that classified tropical vegetation, including forests, into a variety of (nonoverlapping) age classes and is reported in detail in Foody et al. (1996). The main diagonal of the matrix represents the instances where the class labels derived from the classification corresponded to those in the ground data. The sum of these correctly allocated cases may be used, relative to the grand total of cases in the testing set, to derive the percentage of cases correctly allocated. In this example the overall percentage of correctly allocated pixels was $79.49 \%$. This gives a simple measure of the overall accuracy of the classification. If the main focus of attention is on the accuracy with which a particular class has been classified, rather than the overall accuracy, this may be estimated on the basis of the ratio of correctly allocated cases to the relevant column or row total in the matrix depending on the analyst's perspective (Story and Congalton, 1986). These accuracies may vary markedly for the same class. For example, the accuracy with which the forests aged 2-3 years class was classified from the producer's and user's perspectives was $96.88 \%$ and $38.75 \%$ respectively. Although simple, such measures are not without problems. The sample design used to derive the testing set, for example, can influence significantly the accuracy statement (Campbell, 1996; Stehman and Czaplewski, 1998). A major concern, however, is that the simple measures of accuracy focus only on the main diagonal of the matrix (highlighted in grey) and make no compensation for chance agreement. To reduce these problems, the kappa coefficient of agreement (Cohen, 1960) has been widely used in remote sensing (Rosenfield and Fitzpatrick-Lins, 1986; Congalton, 1991). For the matrix illustrated, the kappa coefficient is 0.7476. This measure may also be derived for individual classes of interest. The calculation of the kappa coefficient of agreement may also be weighted to accommodate for variations in the magnitude of error (Cohen, 1968) which is valuable as the confusion between some classes may be more damaging than others in remote sensing studies. With a weight associated with all possible allocations that indicates the relative severity of the misallocations, a 
weighted kappa coefficient may be derived. In the example (Foody et al., 1996), this gave weighted kappa coefficient of 0.8569. The kappa coefficient is also not always ideal (Foody, 1992). In particular it is inappropriate for the evaluation of fuzzy classifications where a pixel may have membership to more than one class. As classification accuracy assessment is still a field of active research, care should be taken to provide a thorough description of the data sets and methods used in evaluating a classification to help others interpret the quality of the classification and its appropriateness for the application in-hand.

Figure 5. A typical neural network used for image classification. The neural network acts to convert the remotely sensed imagery into a thematic classification. The network itself consists of a large number of simple processing units arranged in a layered architecture with each unit in a layer linked to every unit in adjacent layers by a weighted connection. There is an input unit associated with each discriminating variable (e.g., spectral waveband) used, one or more hidden layers of processing units and an output layer with one unit associated with each class. The training data and a learning algorithm (e.g., backpropagation) are used to help the network adjust the value of the weighted connections between units until the network can identify correctly class membership from the input data presented to it. Discussion of neural network processing may be found in Schalkoff (1992) and Bishop (1995) and examples of their application in mapping land cover from remote sensing in Benediktsson et al. (1990) and Foody (1996).

Figure 6 . An hypothetical mixing space between three spectral endmembers in a two-dimensional feature space. 


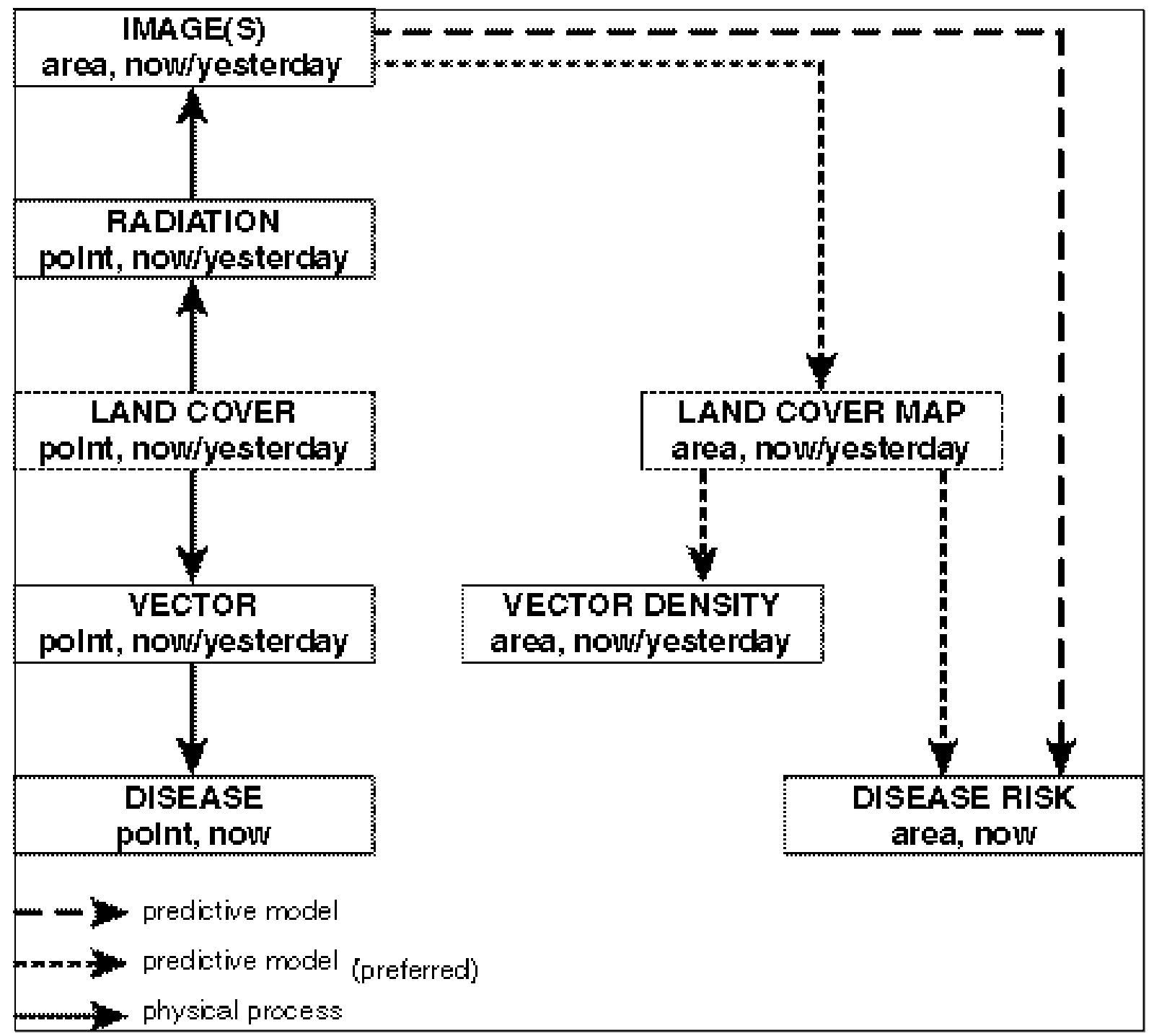

Figure 1 


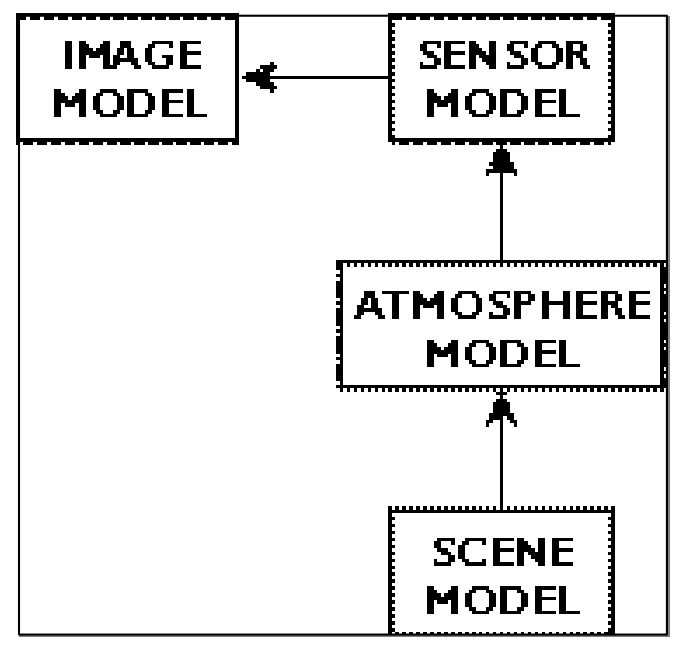

Figure 2 


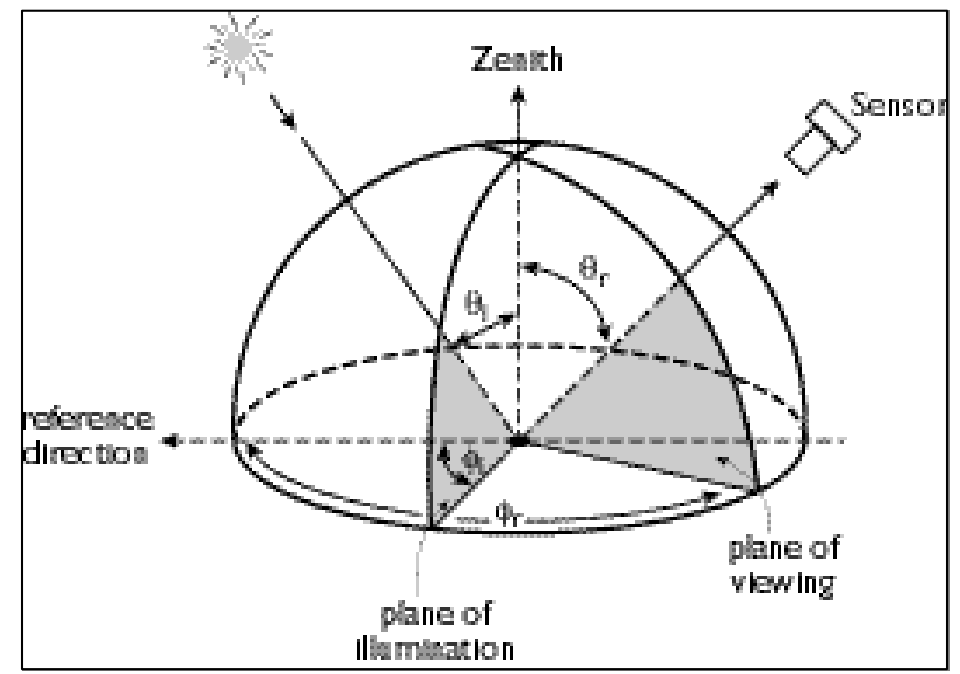

Figure 3 


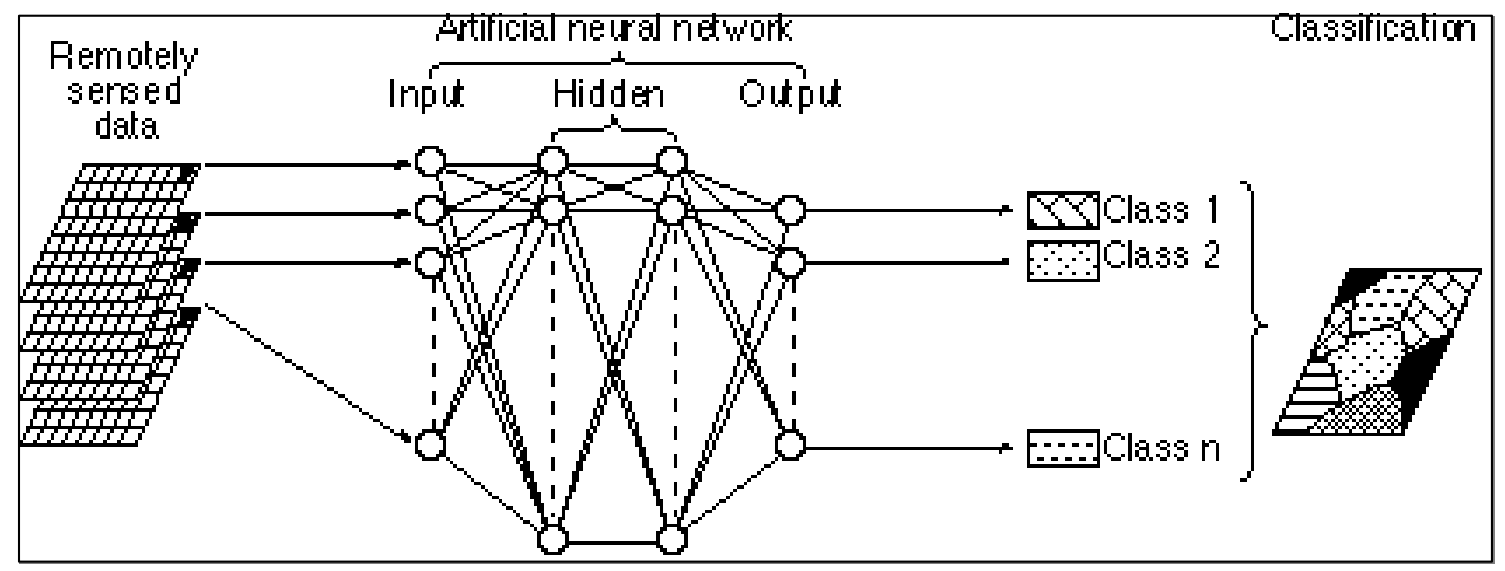

Figure 4 


\begin{tabular}{|c|c|c|c|c|c|c|c|c|}
\hline & & & redcte & d cas & & & & Pnotoness \\
\hline & Pisiofiot & $\therefore 2$ & $2-3$ & $j-t$ & $d-7 t$ & $\therefore 7$ & $\Sigma$ & 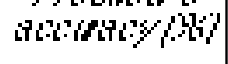 \\
\hline Pasiofizo & 192 & $\mathbf{0}$ & $\mathbf{0}$ & $\mathbf{0}$ & $\mathbf{0}$ & $\mathbf{0}$ & 192 & 100.00 \\
\hline$\therefore 28 \mathrm{ars}$ & $\mathbf{0}$ & 75 & 49 & 13 & 37 & $\mathbf{0}$ & 174 & 43.10 \\
\hline $2-3 \% a r s$ & 1 & $\mathbf{0}$ & $\mathrm{Bj}$ & $\mathbf{0}$ & $\mathbf{0}$ & $\mathbf{0}$ & 32 & 96.88 \\
\hline$\Rightarrow-b / \mathrm{Aa} / \mathrm{s}$ & $\mathbf{0}$ & 1 & $\mathbf{0}$ & 55 & 74 & $\mathbf{0}$ & 130 & 4231 \\
\hline$d-\not A \not A w s$ & $\mathbf{0}$ & $\mathbf{0}$ & $\mathbf{0}$ & 12 & 180 & $\mathbf{0}$ & 192 & $93 . \overline{5}$ \\
\hline$\therefore \not x y+2$ & $\mathbf{0}$ & 0 & $\mathbf{0}$ & $\mathbf{0}$ & $\mathbf{0}$ & 192 & 192 & 100.00 \\
\hline$\Sigma$ & 193 & 76 & 80 & 80 & 291 & 192 & 912 & \\
\hline 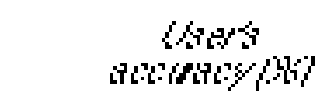 & 99.48 & 98.68 & $38 . \overline{5}$ & $68 . \overline{5}$ & 61.86 & 100.00 & & \\
\hline
\end{tabular}

Figure 5 


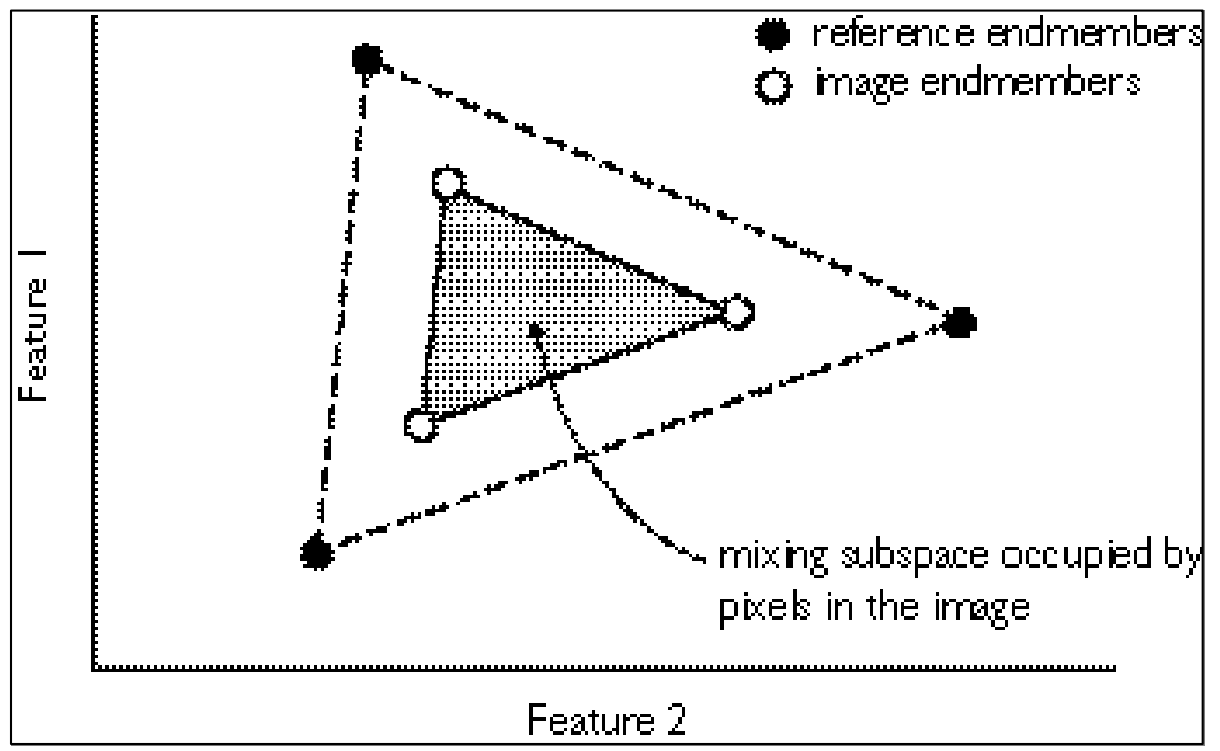

Figure 6 